\title{
Review Article \\ Comparison of Atrial Fibrillation in the Young versus That in the Elderly: A Review
}

\author{
Rajiv Sankaranarayanan,, ${ }^{1,2}$ Graeme Kirkwood, ${ }^{1,2}$ Katharine Dibb, ${ }^{2}$ and Clifford J. Garratt ${ }^{1,2}$ \\ ${ }^{1}$ Unit of Cardiac Physiology, Cardiovascular Research Group, 3rd Floor, Core Technology Facility, \\ The University of Manchester, M139PL, Grafton Street, Manchester M13 9NT, UK \\ ${ }^{2}$ Manchester Heart Centre, Manchester Royal Infirmary, Oxford Road, Manchester M13 9WPL, UK
}

Correspondence should be addressed to Rajiv Sankaranarayanan; rajiv-s@doctors.org.uk

Received 12 June 2012; Accepted 9 August 2012

Academic Editor: Evren Caglayan

Copyright (C) 2013 Rajiv Sankaranarayanan et al. This is an open access article distributed under the Creative Commons Attribution License, which permits unrestricted use, distribution, and reproduction in any medium, provided the original work is properly cited.

\begin{abstract}
The incidence and prevalence of atrial fibrillation $(\mathrm{AF})$ are projected to increase significantly worldwide, imposing a significant burden on healthcare resources. The disease itself is extremely heterogeneous in its epidemiology, pathophysiology, and treatment options based on individual patient characteristics. Whilst ageing is well recognised to be an independent risk factor for the development of $\mathrm{AF}$, this condition also affects the young in whom the condition is frequently symptomatic and troublesome. Traditional thinking suggests that the causal factors and pathogenesis of the condition in the young with structurally normal atria but electrophysiological "triggers" in the form of pulmonary vein ectopics leading to lone AF are in stark contrast to that in the elderly who have AF primarily due to an abnormal substrate consisting of fibrosed and dilated atria acting in concert with the pulmonary vein triggers. However, there can be exceptions to this rule as there is increasing evidence of structural and electrophysiological abnormalities in the atrial substrate in young patients with "lone AF," as well as elderly patients who present with idiopathic AF. These reports seem to be blurring the distinction in the pathophysiology of so-called idiopathic lone AF in the young versus that in the elderly. Moreover with availability of improved and modern investigational and diagnostic techniques, novel causes of AF are being reported thereby seemingly consigning the diagnosis of "lone AF" to a rather mythical existence. We shall also elucidate in this paper the differences seen in the epidemiology, causes, pathogenesis, and clinical features of AF in the young versus that seen in the elderly, thereby requiring clearly defined management strategies to tackle this arrhythmia and its associated consequences.
\end{abstract}

\section{Epidemiology}

There has been a worldwide increase in the ageing population, and as age is the most significant risk factor for AF, AF cases are predicted to reach nearly 16 million in the USA and 25 to 30 million in Europe by 2050 [1,2]. The prevalence of AF shows a strong age dependence varying from $0.5 \%$ in patients aged $<40$ years to $5 \%$ in patients aged $>65$ years and nearly $10 \%$ amongst octogenarians [3-6]. Both the Framingham Heart Study and the Rotterdam Study estimated that the lifetime risk for development of AF in adults $>40$ years and at the age of 55 years respectively to be approximately 1 in $4[7,8]$. The Cardiovascular Health Study which was a large population study of 5201 elderly adults (age $\geq 65$ years) showed an incidence of 17.6 and 42.7 events per 1000 person-years amongst men aged 65 to 74 years and 75 to 84 years, respectively, whereas amongst women in the corresponding age groups, the incidences were 10.1 and 21.6 [9]. The SAFE study which was a UK-based multicentre randomised control trial of elderly ( $\geq 65$ years) patients with AF showed an overall prevalence of $7.2 \%$ and $10.3 \%$ in those aged 75 years and older, with a $1.6 \%$ yearly incidence of new $\mathrm{AF}[10]$.

AF in the young in the absence of identifiable causes can be idiopathic or termed as "lone AF," that is, not associated with comorbidities or obvious cardiac disease. The term "lone AF," itself was first described nearly sixty years back by Evans and Swann [11]. Traditionally the cut-off age of 60 years has also been included in the diagnosis of lone $\mathrm{AF}$ as suggested by ACC/AHA/ESC guidelines [12] and 
used previously in several landmark epidemiological studies such as the Framingham Heart Study [13] and the Mayo Clinic Study [14]. Old age is indeed one of the strongest risk factors for AF [6] but terming adults over 60 years as "elderly" seems rather controversial in this modern age of improving longevity. The rationale for this "threshold age" therefore has to be questioned [15]. At variance with this agebased definition of lone AF, studies such as that by Kopecky et al. have analysed the outcome of lone AF in patients aged over 61 years, mean age 74 years (range, 61-97 years) [16]. As newer aetiologies are uncovered and the existence of "truly lone AF" becomes increasingly controversial [1719], the prevalence of "lone AF" also seems to be steadily "decreasing" in modern studies. A recent study of 3978 AF patients from the Euro Heart Survey by Weijs et al. that excluded age or left atrial size from the definition reported a prevalence of idiopathic AF of 3\% out of 3978 patients [20]. The mean age of patients with idiopathic AF in this study was 58 (SD 14) years and nearly half of these (48\%) were older than 60 years. Similarly a 30-year follow-up study reported by the Mayo Clinic reported that lone AF constituted only $2 \%$ of the total proportion of patients with AF [14]. In contrast, earlier studies showed that lone AF occurs in $1.6 \%$ to $30 \%$ of all cases of AF, depending on the definition of idiopathic AF or inclusion criteria used [13, 21-23].

\section{AF Aetiology in the Young}

Lone AF is a diagnosis of exclusion for which any clinical features of comorbidities or structural cardiac abnormalities that could cause AF must be ruled out. Novel risk factors for $\mathrm{AF}$ are increasingly being discovered such as genetic causes, lifestyle factors (such as alcohol consumption, personality traits, and smoking), body mass index, and physical activity, thereby all refuting the diagnosis of "lone AF." In addition, it can also be argued that occult cardiac pathologies such as hypertension or ischaemic heart disease may well be diagnosed in these patients if they are investigated thoroughly.

2.1. Familial. Nearly seven decades ago, Wolff described a case of familial AF in three brothers [24] and since then studies have found a positive family history of AF in up to a third of AF patients $[25,26]$. Having a positive family history especially in younger patients nearly doubles the risk of developing AF [27]. In 1997, Brugada et al. described the first genetic locus on chromosome 10q22-24 in a family with AF segregated as an autosomal dominant trait [28]. In the last few years, genomewide association studies for AF have shown SNPs (small nuclear polymorphisms) at three genetic loci-4q25, 16q22, and 1q21 (reviewed in [29]). Monogenic forms of AF have also been described due to mutations of genes encoding for potassium channels (KCNQI, KCNE2, KCNJ2, and KCNA5), sodium channel gene SCN5A, K(ATP) gene, the ABCC9 gene, and the connexin 40 gene GJA5 [3036]. Attempts to further unravel the interplay of genomics and $\mathrm{AF}$ have shown that the genetic basis of $\mathrm{AF}$ is both complex and heterogeneous.
2.2. Alcohol. The "holiday heart syndrome" was described in 1978 by Ettinger to explain the association between supraventricular tachyarrhythmias particularly $\mathrm{AF}$ and episodes of increased alcohol consumption during weekends and holiday binge drinking by people without structural heart disease [37]. Overall chronic heavy alcohol consumption ( $>36 \mathrm{~g} /$ day) has been shown to increase risk of AF in several studies including the Framingham cohort (reviewed in $[17,38]$ ). Mechanisms of acute alcohol-induced AF include metabolic acidosis, catecholamine release, and electrolyte disturbances whereas chronic overconsumption leads to myocardial fibrosis, dilatation, and autonomic changes [38]. Binge drinking is particularly prevalent amongst young people and alcohol has been identified to potentiate paroxysmal AF in up to two-thirds of cases [39]. In the elderly, the relationship between $\mathrm{AF}$ and alcohol intake is more complex however. The Cardiovascular Health Study showed an inverse association between alcohol consumption and risk of $\mathrm{AF}$ in patients over 60 years old, with a $4 \%$ lower risk for each additional drink per week [9]. Other studies have also shown a lack of association between risk of developing $\mathrm{AF}$ and moderate alcohol consumption [40,41].

2.3. Obesity. A meta-analysis by Wanahita et al looking at 16 studies that enrolled 123249 individuals (mean age $56 \pm 2$ years) demonstrated a $49 \%$ increased risk of developing $\mathrm{AF}$ due to obesity (relative risk 1.49, 95\% CI 1.36-1.64) [42]. Obesity-associated left ventricular hypertrophy and left atrial dilation are postulated to be important causes which lead to AF $[43,44]$. A 3-8\% increased risk of developing AF has been associated with each unit increase in body mass index [45, 46]. Obstructive sleep apnoea which is also associated with obesity has been shown to portend risk of AF development in individuals $<65$ years of age [47]. The association between obesity and lone AF is not robust however [19] and in fact taller and leaner adults are reported to be more prone to develop lone AF [42, 48].

2.4. Sports and Physical Activity. AF has been recognised to be the commonest cause of palpitations amongst young athletes [49]. Endurance athletes such as marathon runners have been shown to have a greater predisposition to develop AF when compared to nonathletes [48, 50-52]. Karjalainen et al. diagnosed lone $\mathrm{AF}$ in $5.3 \%$ out of a cohort of 228 male cross-country runners (mean age 47.5 years) [53]. Mont et al. reported a four times higher proportion of sports enthusiasts who had lone AF (aged $<65$ years) in comparison to controls in a Catalonian population (63\% versus $15 \%)$ [51]. The same group reported that $>1500$ lifetime hours is the threshold for increased AF propensity [52]. In more than half of the sportsmen with lone AF, a likely vagal precipitant was identified (postprandial, postexercise or at rest). Interestingly, in the recent GIRAFA study, cumulative work-related moderate-to-heavy physical activity has also been shown to predict risk of developing lone $\mathrm{AF}$ in middle aged men aged $<65$ years [48]. A meta-analysis of six case control studies, including 655 athletes and 895 controls (predominantly men), with a mean age of $51 \pm 9$ years showed 
a significantly higher risk of $\mathrm{AF}$ in athletes $(\mathrm{OR}=5.29$; 3.57-7.85; $P=0.0001$ ) [54]. Increased left atrial volume was shown to strongly predict AF in athletes [54]. Mechanisms for sports-induced AF postulated include enlarged left atrium and left ventricular mass [17], increased vagal tone leading to bradycardia as well as shorter atrial refractory period [17] and hypovolemia [55].

2.5. Cardiac Pathologies. There are a variety of cardiac pathologies associated with AF in the young. These include hypertrophic cardiomyopathy which confers a four-to sixfold greater risk of $\mathrm{AF}$ [56]. Prevalence of $\mathrm{AF}$ in these patients is relatively high at about $22 \%$ and incidence is $2 \%$ annually [56]. Even in this pathology, prevalence increases with age and is seen predominantly in the elderly ( $>60$ years age) [56]. Congenital Heart Disease is another risk factor for AF and with improved surgical outcomes, increasing numbers of infants and children are surviving into adulthood. A large Quebec-based population study of about 38000 adult congenital heart disease patients, with a median age of 42 years, showed a prevalence of atrial arrhythmias of $15.1 \%$ (three times greater than that seen in the general population [57]). Wolff-Parkinson-syndrome, myocarditis, pericarditis, and dilated cardiomyopathy are some of the other causes of AF in the young. Valvular heart disease secondary to rheumatic fever is also a significant cause of $\mathrm{AF}$ in the young in the developing world.

2.6. Other Risk Factors. Behavioural or emotional triggers such as Type A personality [58], stress [58], anger, and hostility in men [59] have also been shown to predispose to development of AF. Other risk factors associated with AF include increased coffee and nicotine consumption [17, 58, 60]. The association with caffeine intake is debatable however as a canine study showed inverse association between risk of $\mathrm{AF}$ and intravenous caffeine and no causative role was found in the Danish diet, cancer, and health study [61, 62]. Smoking has been shown to lead to atrial fibrosis which is well recognised to portend AF [63]. Endocrine causes of AF in the young include hyperthyroidism and phaeochromocytoma.

\section{AF Aetiology in the Elderly}

As shown in the Framingham Heart Study, AF is usually secondary to a variety of cardiac pathologies (ischaemic heart disease, heart failure, and valvular heart disease) as well as systemic disorders (hypertension, diabetes, hyperthyroidism) $[6,64]$. This is particularly true in the elderly who also have an increased predisposition of these conditions. However even accounting for other comorbidities, ageing is the strongest independent risk factor that predisposes to $\operatorname{AF}[6,65]$. The Cardiovascular Health Study showed that the prevalence of AF was $9.1 \%$ in the subgroup with clinical cardiovascular disease, $4.6 \%$ in the subgroup with only subclinical cardiovascular disease, and $1.6 \%$ in the absence of clinical or subclinical cardiovascular disease (i.e., lone AF) [22]. Independent risk factors for $\mathrm{AF}$ in the elderly included age, treated systemic hypertension, congestive cardiac failure, valvular heart disease, stroke, enlarged left atria size, mitral or aortic valve dysfunction, echocardiographic features of diastolic dysfunction, and raised serum levels of NT-proBNP [22, 66, 67]. Hyperthyroidism is another cause of atrial fibrillation in the elderly and one study reports an AF incidence of $25 \%$ amongst hyperthyroid patients older than 60 years in comparison to $5 \%$ in those aged less than 60 years [68].

\section{Pathophysiology of Lone AF}

AF initiation and maintenance is the result of pulmonary vein repetitive activity (triggers), atrial abnormalities (substrate), and remodelling. Lone AF is likely to be initiated and maintained by the interplay of pulmonary vein ectopics and the posterior wall of the left atrium [69, 70]. Any substrate abnormalities noted have previously been attributed to AFinduced structural remodelling rather than deemed to have a causative role in initiating lone AF. There is increasing evidence however of structural as well as electrophysiological abnormalities in the substrate (i.e., atrium) as well in lone AF. For instance, atrial biopsies in such patients have shown fibrotic changes and even other occult pathologies such as myocarditis [71, 72]. More recently, electrophysiological studies in patients with a history of paroxysmal lone AF remote from the arrhythmia have also shown abnormalities strongly suggestive of dysfunctional atrial conduction involved in AF initiation and progression [73]. These include larger atrial volumes, longer effective refractory period, longer conduction time along linear catheters, longer biatrial activation time, slower conduction velocity, larger proportion of fractionated electrograms, longer corrected sinus node recover time, and lower mean atrial voltage [73]. Another study of early onset lone AF patients (age less than forty years old) showed a significant difference in $\mathrm{P}$ wave morphology thereby implying abnormal interatrial conduction [74]. These findings seem to implicate a causative role for altered atrial electrophysiology in initiating lone AF. However as AF-induced electrical remodelling is well recognised to start early within a few hours of the onset of $\mathrm{AF}$ [75], there remains the possibility that these changes could be secondary to very early remodelling. For instance, previous experiments in a goat model of paroxysmal AF by Garratt et al. showed that it takes between 5 days to 4 weeks to develop changes in atrial substrate which then self-perpetuate $\mathrm{AF}[76$, 77]. A variety of studies have also implicated inflammation in having an aetiological role in the initiation and perpetuation of atrial fibrillation due to evidence of raised inflammatory markers such as interleukin- 6 and C-reactive protein in AF patients $[78,79]$. In view of the multiple confounding factors and comorbidities associated with inflammation, the jury is still out whether it is a cause or consequence of AF [80]. Structural remodelling as a consequence of AF can cause calcium overload and atrial myocyte apoptosis leading to an inflammatory response [81]. In lone AF patients, there have been contradictory results such as from a large study by Ellinor et al. that showed no difference in high sensitive CRP [82] but others have noted high levels of CRP and high sensitive CRP in lone AF patients [83, 84]. Significantly, however, Aviles et al. included patients with hypertension in their 
definition of lone AF albeit with overtly structurally normal hearts. This could have been a significant confounding factor as hypertension itself is associated with inflammation [83]. Myocardial perfusion imaging in patients with lone recurrent AF has shown isolated perfusion abnormalities indicative of microvascular dysfunction [85]. Echocardiography has also shown evidence of left ventricular diastolic dysfunction in patients thought to have idiopathic AF [86].

\section{Electrophysiological and Structural Alterations in Aged Atria}

5.1. Initiation of AF in the Aged Atria. A number of studies (summarised in Table 1) have attempted to unravel the atrial electrophysiological characteristics of aged atria in relation to AF. Whilst most animal and human studies have shown that aged atria have an increased propensity to develop AF [87-93], some studies in elderly AF patients have yielded conflicting results although these could have been influenced by underlying pathology or treatment in patients [94-96]. Increased atrial ERP has been noted in these studies which could be sufficient to overcome any other arrhythmogenic remodelling. There is therefore a need to understand, in the absence of underlying disease, how AF is initiated and maintained in the aged atria.

5.2. Initiation of AF. Why the aged atria are more susceptible to the development of AF in the absence of other risk factors remains poorly understood. We shall describe below how ageing may increase the propensity of both (i) triggered activity in the form of DADs and (ii) reentrant circuits.

5.3. Delayed after Depolarizations (DADs) in the Aged Atria. Potential contributory factors that may predispose to DAD formation and indeed the increased incidence of DADs have been demonstrated in some models of ageing [90, 93]. Wongcharoen et al. observed DADs of greater amplitude in aged rabbit LA pulmonary vein sleeve tissue sections associated with an increase in NCX protein which would provide an additional means to facilitate triggered activity as more depolarising current would flow during any spontaneous $\mathrm{Ca}^{2+}$ release and therefore, all things being equal, a smaller spontaneous release would produce a bigger DAD [90]. Some other studies have also described evidence of atrial calcium mishandling in AF (Table 1) [97]. This has been attributed to protein kinase A-induced hyperphosphorylation leading to dysfunctional ryanodine receptor [98]. While decreased SERCA and increased RyR protein expression give us clues to SR function, it would also be of interest to understand how $\mathrm{SR} \mathrm{Ca}^{2+}$ content responds to age in the pulmonary vein. One study using human atrial tissue from elderly patients (mean age 68 years) has suggested that hyperphosphorylation of phospholamban could be contributory to leaky ryanodine receptors and thus abnormal calcium handling in chronic AF patients [99]. Clearly there is a pressing need to understand how $\mathrm{Ca}^{2+}$ homeostasis is achieved in the aged atria and how it is subsequently remodelled in the aged atria in AF.
5.4. Reentrant Circuits in the Aged Atria. A reentrant substrate can result from altered functional (electrical) properties or structural changes to the atrium and these are discussed below with reference to ageing.

5.4.1. Effective Refractory Period (ERP). Whilst conflicting results have been noted when analysing the effects of ageing on effective refractory period in both human $[95,96,100$, $101]$ as well as animal right atria $[92,102,103]$, review of various studies indicates that the right atrial ERP is prolonged with ageing [104]. Inconsistency in the literature may relate to variation in anatomical sites studied [105] and, in terms of patient studies, the effects of underlying disease, arrhythmias, drug treatment, or a general lack of studies including very elderly patients as highlighted by Dun and Boyden [104]. The few studies investigating action potential duration (APD) or ERP in aged left atrium also show conflicting results [106, 107]. Furthermore in rabbit pulmonary vein sleeves and left atrial posterior wall APD was prolonged with age [90, 91]. Electrical characteristics and age-associated remodelling of the atrium appear to be region specific [93] and this may underlie differences between the above studies. Interestingly while the prolonged action potential in aged rabbit left atrial posterior wall may be expected to be anti-arrhythmogenic, this gave rise to an increase in APD dispersion (discussed below) which was suggested to potentiate AF [91].

Many ion channels have yet to be studied in the aged atria and work mainly performed in the dog has shown that there is no age-related change in sodium current density [108]. However $I_{\mathrm{Ca}-\mathrm{L}}$ is depressed, which would be expected to depress the plateau of the action potential [92], and since repolarising currents activate more strongly at positive potentials, this may slow activation and prolong repolarisation, thus prolonging ERP. Of the repolarising currents only $I_{\text {to }}$ has been assessed and peak as well as sustained $I_{\text {to }}$ was increased with age in the right atrium [109] but not the left atrium [104]. Indirect evidence suggests $I_{\mathrm{KACH}}$ may be enhanced in the right atrium with age [103]; however there are no studies investigating age-associated changes in $I_{\mathrm{K} 1}, I_{\mathrm{Kur}}, I_{\mathrm{Kr}}$ and $I_{\mathrm{Ks}}$, in either atria.

5.4.2. Conduction Velocity. A number of studies have reported age-associated general or directional conduction slowing and resultant spiral-reentrant waves in the right atria mainly in tissue strips but also in vivo in various species $[100,111]$. In the aged dog, conduction of normal beats was unaltered but premature impulses were slowed suggesting a certain amount of depolarizing current is needed to overcome conduction discontinuities in age [92]. By calculating conduction in the direction of the wavefront, Kojodjojo et al. have shown in human atria that increasing age is associated with decreased propagation velocity in both atria during sinus rhythm and also during pacing [107]. In this respect the reduction of $I_{\mathrm{Na}}$ noted in $\mathrm{AF}[112,113]$ is potentially significant as it will slow conduction velocity and reduce the excitation wavelength. Based on a very limited number of studies the effects of ageing on peak $I_{\mathrm{Na}}$ are inconsistent, showing either no change at low stimulation frequencies but 
TABLE 1: Studies investigating relationship between atrial electrophysiological changes and ageing.

\begin{tabular}{|c|c|c|c|}
\hline Authors & Species & Characteristics & Key findings \\
\hline $\begin{array}{l}\text { Brembilla-Perrot et al. } \\
{[96]}\end{array}$ & Human & Patients aged $>70$ years versus younger & $\begin{array}{l}\text { Decreased AF inducibility due to increased } \\
\text { atrial ERP }\end{array}$ \\
\hline $\begin{array}{l}\text { Centurión et al. } \\
\text { [89] }\end{array}$ & Human & $\begin{array}{l}\text { Patients with paroxysmal AF during sinus } \\
\text { rhythm aged }>60 \text { years versus younger }\end{array}$ & $\begin{array}{l}\text { Greater mean number of abnormal right } \\
\text { atrial electrograms defined as } \geq 100 \mathrm{msec} \\
\text { duration and, or showing eight fragmented } \\
\text { deflections }\end{array}$ \\
\hline $\begin{array}{l}\text { Roberts-Thomson } \\
\text { et al. [87] }\end{array}$ & Human & Patients aged $>60$ years versus younger & $\begin{array}{l}\text { Greater number of complex fractionated } \\
\text { electrograms }\end{array}$ \\
\hline Sakabe et al. [94] & Human & $\begin{array}{c}\text { Patients without a history of AF or } \\
\text { structural heart disease }\end{array}$ & $\begin{array}{l}\text { No relationship between age and } \\
\text { inducibility of AF }\end{array}$ \\
\hline \multicolumn{4}{|c|}{ Calcium mishandling } \\
\hline $\begin{array}{l}\text { El-Armouche et al. } \\
\text { [99] }\end{array}$ & Human & $\begin{array}{l}\text { Western blotting used to assess } \\
\text { phosphorylation levels of Ca handling } \\
\text { proteins in right atrial appendage }\end{array}$ & $\begin{array}{l}\text { Hyperphosphorylation of phospholamban } \\
\text { could be contributory to leaky ryanodine } \\
\text { receptors and thus abnormal calcium } \\
\text { handling in chronic AF patients }\end{array}$ \\
\hline $\begin{array}{l}\text { Hove-Madsen et al. } \\
\text { [97] }\end{array}$ & Human & Age $>66$ years & $\begin{array}{l}\text { Higher calcium spark frequency and higher } \\
\text { incidence of spontaneous calcium waves in } \\
\text { comparison to patients with sinus rhythm }\end{array}$ \\
\hline Ono et al. [88] & Rats & Old versus young rats & $\begin{array}{l}\text { Glycolytic inhibition has been shown to } \\
\text { result in spontaneous AF due to calcium } \\
\text { mishandling and early after } \\
\text { depolarisation-induced triggered activity }\end{array}$ \\
\hline $\begin{array}{l}\text { Wongcharoen et al. } \\
{[90]}\end{array}$ & Rabbits & $\begin{array}{l}\text { Responses of pulmonary vein tissues to } \\
\text { rapamycin, FK-506, and ouabain in young } \\
\text { and aged rabbits }\end{array}$ & $\begin{array}{l}\text { Increased pulmonary vein arrhythmogenesis } \\
\text { secondary to ryanodine receptor } \\
\text { dysfunction-resultant calcium mis-handling }\end{array}$ \\
\hline \multicolumn{4}{|c|}{ Atrial ERP } \\
\hline Kistler et al. [100] & Human & $\begin{array}{c}\text { Electrophysiological and electroanatomical } \\
\text { studies in } 3 \text { age groups ( } \geq 60 \text { years, } 31-59 \\
\text { years, and } \leq 30 \text { years) }\end{array}$ & $\begin{array}{l}\text { Age-associated electrical and structural } \\
\text { remodeling (regional conduction slowing, } \\
\text { increase in atrial ERP, impaired sinus node } \\
\text { function, conduction delay at crista } \\
\text { terminalis, and areas of low voltage) }\end{array}$ \\
\hline $\begin{array}{l}\text { Brembilla-Perot et al. } \\
{[96]}\end{array}$ & Human & $\begin{array}{c}734 \text { patients (age } 16-85 \text { years, mean } 61 \pm 15 \\
\text { years) }\end{array}$ & $\begin{array}{l}\text { Increased atrial ERP and age }>70 \text { years } \\
\text { independently predicted reduced AF } \\
\text { inducibility }\end{array}$ \\
\hline $\begin{array}{l}\text { Brorson and Olsson } \\
{[101]}\end{array}$ & Human & $\begin{array}{l}\text { Right atrial monophasic action potentials } \\
\text { recorded in } 40 \text { healthy males }\end{array}$ & No age correlation \\
\hline $\begin{array}{l}\text { Anyukhovsky et al. } \\
\text { [92] }\end{array}$ & Dogs & Young versus old canine atrial & $\begin{array}{l}\text { Age-related differences in action potential } \\
\text { contour, decreased } I_{\mathrm{CaL}} \text {, and slower } \\
\text { conduction of early premature beats }\end{array}$ \\
\hline Huang et al. [106] & Rats & Adult, middle aged versus aged rats & $\begin{array}{l}\text { Age-associated prolongation of the } \\
\text { monophasic action potential (mAP) and } \\
\text { ERP in the right atrium, but a decrease in } \\
\text { mAP and ERP in the left atrium, suggesting } \\
\text { a potential reentrant mechanism for AF }\end{array}$ \\
\hline Kojodjojo et al. [107] & Humans & $\begin{array}{l}\text { Most study subjects suffered from } \\
\text { atrioventricular reentrant arrhythmias, } \\
\text { syncope, or palpitations and hence these } \\
\text { atria were not "healthy" }\end{array}$ & No change in left atrial ERP with ageing \\
\hline Michelucci et al. [105] & Humans & 17 normal subjects (age range $17-78$ years) & Age-related increase in right atrial ERP \\
\hline Su et al. [103] & Rats & Adults versus aged rats & $\begin{array}{l}\text { In response to muscarinic stimulation, } \\
\text { ageing-related prolongation of atrial } \\
\text { maximum diastolic potential but not of APD }\end{array}$ \\
\hline Toda [102] & Rabbit & Rabbit ages varied from $2-360$ days old & Age-related prolongation of APD \\
\hline
\end{tabular}


TABLE 1: Continued.

\begin{tabular}{|c|c|c|c|}
\hline Authors & Species & Characteristics & Key findings \\
\hline \multicolumn{4}{|c|}{ Ion channel remodelling in ageing and $\mathrm{AF}$} \\
\hline $\begin{array}{l}I_{\mathrm{CaL}} \text { Anyukhovsky } \\
\text { et al. }[92]\end{array}$ & Canine atria & & Reduced $I_{\mathrm{CaL}}$ \\
\hline$I_{\mathrm{Na}}$ Baba et al. [108] & Canine atria & & $\begin{array}{l}\text { (i) Peak current unchanged at low } \\
\text { stimulation frequencies but reduced a } \\
\text { stimulation frequencies relevant to } \mathrm{AF}\end{array}$ \\
\hline Wu et al. [110] & Rabbit atria & & $\begin{array}{l}\text { (ii) Decreased in hyperlipidemic aged } \\
\text { rabbits }\end{array}$ \\
\hline$I_{\text {to }}$ Dun et al. [109] & Canine atrium & & Increased in the left atrium \\
\hline$I_{\text {KAch }}$ Su et al. [103] & Rat & & Indirect evidence of increase [104] \\
\hline
\end{tabular}

reduced at stimulation frequencies relevant to $\mathrm{AF}(10 \mathrm{~Hz})$ [108] or a decrease [110].

Changes in connexin expression (especially Cx40 and Cx43) have been noted in AF-related remodelling [114] and are also noted in ageing [115]. A single study has shown an age-associated decrease in connexin 43 in the sinoatrial node but unaltered expression of connexins in the right atria [115]. However a change in the distribution of connexins away from the lateral cell edges to the intercalated discs has also been noted in ageing [116]. This is potentially significant, as it will result in anisotropic propagation of excitation and the formation of reentrant circuits [114, 117].

Increased or heterogeneous fibrosis, often associated with advancing age $[92,111]$, can disrupt the coupling between individual myocytes and result in non homogenous conduction or conduction slowing which can lead to re-entry (for review see [118]). Recent work has demonstrated increased AF stability in long-term AF in goats due to "microfibrosis" separating myocyte bundles [119]. Conduction abnormalities can occur following redistribution without altered expression [120].

5.4.3. Dispersion of Conduction Velocity and ERP. ERP dispersion and conduction heterogeneity correlate with AF inducibility and both have been shown to increase with ageing $[91,93,105]$.

In summary, what induces and sustains AF in the young may be different to that in the old. Anyukhovsky et al. showed in old dogs that atrial tissue was depolarised, with longer APD and a slower max upstroke and greater variability in APD. In chronic AF both young and old, the atrial cell membrane was hyperpolarised, with slowed upstroke and decreased APD. But chronic AF led to an increase of APD dispersion in adults and a decrease in old dogs. Thus, AF was sustained in two different substrates: one with short AP duration and with expanded heterogeneity of AP parameters (adult) and one with short AP duration but limited heterogeneity (old). These data also suggest that the increased dispersion in atrial electrophysiology that occurs in adults may be an important additional contributory factor for AF stabilization at this age, while the occurrence of fibrosis and slowed conduction of premature beats that has been demonstrated previously may be more contributory in the old. Table 2 summarises the atrial electrophysiological differences between the elderly versus the young in relationship to the propensity to develop AF.

Histological changes in healthy elderly patients with AF include increased deposition of collagen, adipose tissue and amyloid, atrophy and vacuolar myocyte degeneration and fibrofatty substitution of the sinoatrial node (reviewed in [118]). Aging-related oxidative damage has been shown to portend atrial fibrillation through mitochondrial bioenergetic dysfunction [121]. Imaging studies have also shown agerelated dilatation of the pulmonary veins and the atrium, thereby potentiating pulmonary vein triggers as well as substrate-induced AF maintenance through mechanoelectric feedback $[122,123]$.

\section{Clinical Features}

The clinical presentation of AF varies significantly depending on age and comorbidities. In the young, the initial presentation is usually with paroxysmal AF [124]; persistent AF under the age of 50 is often associated with identifiable causes like structural heart disease, hyperthyroidism, or alcohol excess. Whilst the incidence of both paroxysmal and persistent AF increases dramatically over the age of 60 , there is a disproportionate increase in chronic forms [125], with the result that $80 \%$ of newly diagnosed AF in octogenarians is of a persistent or permanent form, even in the absence of structural heart disease [126]. Moreover, advanced age is a risk factor for early recurrence after first AF presentation and of rapid progression from paroxysmal to persistent AF $[125,127]$.

AF is classically associated with "typical" symptoms of irregular palpitations, with or without chest pain, breathlessness, or dizziness. Palpitations are reported in $80 \%$ of young patients with paroxysmal AF. [128]. In contrast, less than $10 \%$ of AF patients over the age of 80 years have palpitations [129] and up to $40 \%$ of elderly hospital inpatients found to have AF are entirely asymptomatic [130]. Whilst atypical chest pain is relatively common in young AF patients, in elderly patients anginal chest pain during AF episodes strongly suggests the presence of significant concurrent coronary disease [131] and might be sufficient to warrant investigation for coronary ischaemia even in the absence of typical symptoms of angina.

AF in elderly patients is frequently diagnosed coincidentally during general health assessment, hospital admission for 
TABLE 2: Electrophysiological differences between the elderly and young that can predispose to AF (summarised from human and animal studies in Table 1).

\begin{tabular}{lcc}
\hline Features & Elderly & Young \\
\hline Impulse initiation & & \\
(i) Sinus node function & $\begin{array}{c}\text { Impaired (leading to longer sinus node } \\
\text { recovery times), contributing to } \\
\text { abnormal impulse initiation } \\
\text { Also contributes to AF pathogenesis } \\
\text { (ii) Pulmonary vein ectopic activity }\end{array}$ & $\begin{array}{c}\text { Generally preserved } \\
\text { dominant role in initiation and } \\
\text { maintenance }\end{array}$ \\
\hline
\end{tabular}

Impulse conduction

(i) P wave morphology and duration

(usually signifying interatrial conduction)

Abnormal P wave morphology and prolonged interatrial conduction

Abnormalities noted such as conduction slowing (particularly of premature impulses) thereby contributing to reentrant waves

\section{Substrate abnormalities}

(i) Complex fractionated atrial electrograms

(ii) Atrial refractoriness-effective Refractory Period (ERP)

(iii) Action potential duration (APD)

(iv) Regional atrial voltage differences

\section{Greater number}

ERP prolonged in the right atrium and could contribute to dispersion in refractoriness

Prolonged in the right atrium

Larger atrial volumes with more number of low voltage areas
Usually normal

Usually normal

Lesser than in elderly

Usually not prolonged

Generally within normal limits

Atria usually of normal size and mean voltage within normal limits nonrelated illnesses, or as a result of its complications [132]. A recent randomized controlled study in primary care suggests that implementing targeted opportunistic screening of over 65 -year olds, based on a simple annual pulse assessment, is likely to be cost-effective in improving AF detection [10].

\section{Management of AF}

7.1. General Principles. The management of AF is concerned with two main aspects; symptom relief (through rate or rhythm control) and prevention of complications. Although certain complications, such as left ventricular dysfunction, may be reduced by these therapies, the prevention of thromboembolic events requires targeted and appropriate antithrombotic therapy. AF management including stroke prevention is dependent on multiple factors including patient age, comorbidities, and disease profile.

7.2. Stroke Risk, Bleeding Complications, and Anticoagulation. $\mathrm{AF}$ is associated with a 5-fold increase in the risk of strokes, and strokes due to AF are associated with higher mortality and worse functional outcome [133]. Age has a particularly dramatic impact on the risk of AF-associated stroke: between the ages of 50-59 the average lifetime risk is $5 \%$ and $3.9 \%$ for men and women, respectively, and this rises exponentially to $22.3 \%$ and $23.9 \%$ between 80 and 84 [134]. Vitamin K antagonists (usually warfarin) or other oral anticoagulants (see below) reduce the risk of strokes by around 60-70\%, albeit at the risk of intracranial haemorrhage and other bleeding-related complications $[135,136]$.

$\mathrm{AF}$ in the context of mitral valve stenosis, or a prosthetic mitral valve, is considered to be extremely high risk, and anticoagulation is mandatory in the absence of clear contraindications [136]. For nonvalvular AF, the CHADS2 score was introduced in 2001 as a simple scoring system to assess the stroke risk (see Table 3) [137]. However, the influence of age is underestimated by the CHADS2 system; recent studies have indicated that, amongst moderate risk patients with a CHADS2 score of 1 , individuals over the age of 75 with isolated AF are at a higher risk of stroke than are younger patients with a single additional risk factor $[138,139]$. Therefore a more comprehensive scoring system called CHA(2)DS(2)VASc has been recommended in recent guidelines (see Table 4) [140]. By recognizing a spectrum of major and minor risk factors that warrant treatment with anticoagulation, this system more accurately identifies individuals at truly low risk and extends the use of anticoagulation into the previous medium risk category. Notably, using the CHA(2)DS(2)VASc, anticoagulation is considered to be potentially beneficial for all patients aged over 65 years, whilst the decision in younger patients depends on additional risk factors.

Although most AF patients are elderly, until recently these patients have been somewhat underrepresented in clinical trials of anticoagulation. The clinical benefit from 
TABLE 3: CHADS2 scoring system [137].

\begin{tabular}{lcc}
\hline & Comorbidity & Score \\
\hline C & Congestive heart failure & 1 \\
H & Hypertension & 1 \\
A & Age $\geq 75$ years & 1 \\
D & Diabetes mellitus & 1 \\
S2 & Stroke or TIA & 2 \\
\hline
\end{tabular}

CHADS2 score 0; annual stroke risk 1.9\%, >1; annual stroke risk $2.8=18.2 \%$.

anticoagulation not only persists but potentially increases with advanced age; for example, the recent ATRIA study demonstrated that AF patients aged over 75 years benefit most from warfarin treatment in terms of absolute and relative reduction in stroke rate [141]. Despite this clear evidence of benefit, anticoagulation is considerably underutilised in this age group, typically with only one-third of over $85 \mathrm{~s}$ receiving appropriate therapy despite an absence of definite contraindications [142].

In physician studies, the most commonly reported concerns with anticoagulation are perceived bleeding risk and a history of falls [143]. Elderly patients certainly do have an increased risk of bleeding complications [144], and whilst all forms of bleed have a potential associated mortality and morbidity, the main concern is intracranial haemorrhage. Although this complication is relatively rare even in the elderly $(<1 \%$ per year in the BAFTA trial of patients over 75 years old), nevertheless it constitutes $90 \%$ of anticoagulationrelated deaths [145]. Careful monitoring and control of anticoagulation can improve this balance; the risk of intracranial haemorrhage is only modestly increased with a therapeutic INR between 2-3 but rises sixfold when the INR rises above 3.5. Conversely, targeting a subtherapeutic INR of $<1.8$ results in a sevenfold reduction in stroke prevention without a reduction in intracranial haemorrhage risk (thus equating to a loss of clinical effectiveness and worse outcomes). "Realworld" studies of anticoagulation in octogenarians, report that the risk of major bleeding (either fatal or requiring transfusion) is 13.1 per 100 patient-years [146]. Whilst this is higher than the rate of 4.7 per 100 patient years seen in younger patients, the highest risk of bleeding was seen in patients with a high CHADS2 score of $\geq 3$. Thus patients who are at highest risk of bleeding are also those who potentially benefit the most in terms of stroke reduction, and the absolute risk reduction in stroke-related mortality exceeds the risk increase of fatal bleeds. The perceived risk of anticoagulation in patients with a history of falls is probably exaggerated; whilst there is a slight excess of nonintracranial bleeds in these individuals, a meta-analysis has calculated that a fall rate of at least 300 per year would be required to negate the stroke-prevention benefit [147].

Recently, guidelines have suggested the use of scoring systems such as HASBLED (see Table 5) in order to better assess bleeding risk prior to commencing anticoagulation. A score of $\geq 3$ is considered to represent high risk of bleeding, and caution and careful monitoring recommended [148]. In view of the complexity of managing anticoagulation in the elderly, there has also been substantial interest in alternatives to oral vitamin $\mathrm{K}$ antagonists. However, it is clear that aspirin is significantly less effective than warfarin at preventing strokes, and there appears to be no net benefit over the age of 77 [139]. Recent consensus therefore advises against the use of aspirin for AF thromboprophylaxis [149]. As CHA(2)DS(2)VASc allows identification of patients with an exceedingly low stroke risk, aspirin is now considered to be a nonpreferred alternative for young patients with a single risk factor.

Recently there has been a surge of new anticoagulant alternatives to warfarin. These do not require regular monitoring of clotting profile. Dabigatran is a newly approved oral direct thrombin inhibitor. The RE-LY trial reported that high dose Dabigatran (150 mg b.d.) was more efficacious than warfarin with a similar risk of bleeding complications (intracranial and extracranial), whilst low dose Dabigatran (110 mg b.d.) was noninferior to warfarin with a reduced risk of bleeding [150]. These effects were consistent amongst young and elderly patient subgroups, although there was a slight excess of gastrointestinal bleeds in elderly patients taking higher dose [151]. This drug could therefore provide either improved stroke prevention when used in high doses in young patients or reduced bleeding risk at low doses in the elderly. Rivaroxaban (a factor Xa inhibitor) is another new anticoagulant. The ROCKET-AF trial reported noninferiority to warfarin in nonvalvular AF, with no significant increase in major bleeding and a lesser incidence of intracranial and fatal bleeding in comparison to warfarin [152]. Of particular relevance to the elderly, the median age in this trial was 73 years ( $25 \%$ were $\geq 78$ years). Apixaban, another factor Xa inhibitor, was reported last year in the Aristotle trial (median age 70 years) to be more efficacious than warfarin and also caused less bleeding [153].

7.3. Rate or Rhythm Control? There are two main strategies of management in AF rate control and rhythm control with either pharmacological or nonpharmacological options.

Pharmacological strategies of rate and rhythm control have been compared in multiple studies. Despite clear theoretical benefits of sinus rhythm in the form of improved atrioventricular dynamics and an improvement in cardiac output, there is no significant benefit of a rhythm control strategy in large randomised population studies. Although there have been few investigations exploring the strategies specifically in different age groups, results of five studies are relevant to a consideration of the elderly and have been included in a meta-analysis [154]; this demonstrates a clear trend towards increased mortality associated with a rhythm control strategy in the elderly. Interestingly, the excess deaths do not appear to relate to proarrhythmic effects or specific side effects of the trial drugs, but rather to other factors such as malignancies or lung disease. This suggests that in elderly frail patients, the use of powerful antiarrhythmic with complex drug interactions may uncover latent comorbidities in a form of nonspecific pharmacotoxicity.

Thus, current guidelines clearly favour a rate-control strategy in the elderly. Initial therapies might include either beta blockers or calcium channel blockers, with digoxin 
TABLE 4: CHADS2VAS2C scoring system [140].

\begin{tabular}{lcc}
\hline & Comorbidity & Points \\
\hline C & Congestive heart failure (or left ventricular systolic dysfunction) & 1 \\
H & Hypertension: blood pressure consistently above $140 / 90 \mathrm{mmHg}$ (or treated hypertension on medication) & 1 \\
A2 & Age $\geq 75$ years & 2 \\
D & Diabetes mellitus & 1 \\
S2 & Pascular disease (e.g., peripheral artery disease, myocardial infarction, aortic plaque) & 2 \\
V & Age $65-74$ years & 1 \\
A & Sex category (i.e., female gender) & 1 \\
Sc &
\end{tabular}

TABLE 5: HASBLED scoring system [148].

\begin{tabular}{|c|c|}
\hline Hypertension (BP > 160 without control) & 1 \\
\hline Renal disease (dialysis, transplant, $\mathrm{Cr}>2.6 \mathrm{mg} / \mathrm{dL}$ or $>200 \mu \mathrm{mol} / \mathrm{L}$ ) & 1 \\
\hline Liver disease (cirrhosis, bilirubin $>2 \mathrm{x}$ normal, AST/ALT/AP $>3 \mathrm{x}$ normal) & 1 \\
\hline Stroke & 1 \\
\hline Predisposition to bleeding or previous major bleed & 1 \\
\hline Labile INR (unstable/high INRs, $<60 \%$ time in therapeutic range) & 1 \\
\hline Age $\geq 65$ & 1 \\
\hline Medications (antiplatelets or NSAIDS) & 1 \\
\hline Alcohol excess & 1 \\
\hline \multicolumn{2}{|c|}{ Risk of spontaneous major bleeding (episodes per 100 patient years) } \\
\hline Score $0-1$ & $1.02-1.13$ \\
\hline Score $2-3$ & $1.88-3.74$ \\
\hline Score $\geq 4$ & $\geq 8.7$ \\
\hline
\end{tabular}

added as appropriate where a second agent is necessary. Whilst previous guidelines emphasised the importance of tight control of ventricular rate (resting heart rate below $80 \mathrm{bpm}$ ), it has recently been demonstrated that equivalent outcomes are achieved with a less stringent target of $115 \mathrm{bpm}$ [155]. In elderly patients, where issues such as coexisting conduction system disease, polypharmacology, and renal impairment are common, a more relaxed approach to rate control is likely to reduce the complexity of management, including the need for pacemaker implantation [156].

In patients with drug-refractory symptoms due to permanent AF, pacemaker implantation with atrioventricular node ablation results in symptomatic benefit for up to $83 \%$ of patients including those over the age of 70 [157]. Many elderly patients with AF have conduction system disease and pacemaker implantation is often indicated for bradycardic indications; $\mathrm{AV}$ node ablation in these patients also allows cessation of rate control medications. Moreover, AV node ablation and cardiac resynchronization therapy should also be appropriate where AF coexists with heart failure, with a recent meta-analysis demonstrating significant mortality benefit over pharmacological rate control [158].

Although large clinical studies do not clearly favour either a rate or rhythm control strategy, there are factors that suggest that certain subgroups may benefit from a rhythm control strategy. As older patients with comorbidities demonstrate an excess mortality due to drug-related side effects, so it is arguable that young and otherwise healthy patients should not experience these side effects and therefore experience the full benefits from restoration of sinus rhythm, including improved ventricular function, quality of life, and reduced progression to permanent AF. There is some evidence from studies focusing on younger patients suggesting this to be the case, and a convincing case that where a rhythm control strategy is effective, it is associated with reduced symptoms and improved mortality compared with rate control [159], although the data as yet do not suggest that anticoagulation can safely be withdrawn.

Factors associated with rapid progression of $\mathrm{AF}$ (advanced age and structural heart disease) are also associated with a poor response to rhythm control strategy. Recently, the HATCH scoring system (hypertension, age older than 75 years, previous transient ischemic attack or stroke, chronic obstructive pulmonary disease, and heart failure) has been proposed to identify patients at risk of progression to persistent AF [127]; a HATCH score of $\geq 2$ was associated with a high risk of disease progression despite antiarrhythmic therapy.

Where a rhythm control strategy is considered appropriate, treatment choices are guided by side effects and contraindications rather than expected efficacy. Where there is no underlying structural heart disease, appropriate first line options include dronedarone, flecainide, propafenone, and sotalol [160]. Although amiodarone is a more efficacious antiarrhythmic [161], it is associated with significant pulmonary, liver and thyroid toxicity with a cumulative and 
TABLE 6: Common differences between AF in the young versus elderly.

\begin{tabular}{|c|c|c|}
\hline & AF in the young & AF in elderly patients \\
\hline \multirow{8}{*}{ Causes } & (i) Idiopathic & (i) Ischaemic heart disease \\
\hline & (ii) Genetic & (ii) Heart failure \\
\hline & (iii) Alcohol, smoking & (iii) Valvular heart disease \\
\hline & (iv) Personality traits & (iv) Hypertension \\
\hline & (v) Body mass index & (v) Cardiomyopathies \\
\hline & (vi) Endurance sports & (vi) Hyperthyroidism \\
\hline & (vii) Cardiac pathologies & $\begin{array}{c}\text { (vii) Secondary causes such as post } \\
\text { operative, infection, pulmonary } \\
\text { embolism }\end{array}$ \\
\hline & (viii) Endocrine disorders & (viii) Idiopathic \\
\hline Pathogenesis & $\begin{array}{c}\text { Triggers/pulmonary vein Repetitive } \\
\text { activity }+++ \\
\text { Substrate/atrial abnormalities + }\end{array}$ & $\begin{array}{c}\text { Pulmonary vein repetitive activity }++ \\
\text { Atrial Abnormalities }+++\end{array}$ \\
\hline Clinical features & Usually typical symptoms & Atypical symptoms or asymptomatic \\
\hline Management & $\begin{array}{l}\text { Rhythm control preferred } \\
\text { Thromboprophylaxis usually not required } \\
\text { unless based on CHADS2VASC }\end{array}$ & $\begin{array}{c}\text { Rate control preferred } \\
\text { Thromboprophylaxis usually required } \\
\text { unless contraindicated }\end{array}$ \\
\hline
\end{tabular}

dose-dependent risk; its long-term use in the young therefore requires very cautious consideration.

Dronedarone has recently emerged as an anti-arrhythmic therapy for paroxysmal AF. It appears to be somewhat less efficacious than amiodarone, but associated with less side effects [162]. The recent ATHENA [163] study suggested that dronedarone may impart a benefit in terms of reduced mortality and hospital admission compared to placebo in certain high risk patient groups, but data showing benefit over other anti-arrhythmic therapies are lacking. Importantly, it is also contra-indicated in patients with permanent AF or decompensated heart failure.

In recent years, the major advance in rhythm management has been in nonpharmacological therapy, namely, left atrial ablation. Since the first report by Haissaguerre et al. that pulmonary vein isolation reduced AF recurrence by eliminating spontaneous focal discharges from pulmonary veins that initiated $\mathrm{AF}$, there have been significant advances in ablation techniques [70]. This treatment strategy is particularly efficacious in patients with lone AF and thus the European Society of Cardiology guidelines recommend left atrial ablation (Class IIa recommendation) for symptomatic patients with paroxysmal or persistent AF who have failed to respond to trial of anti-arrhythmic medication [160]. Whilst complications are reported in up to $5 \%$ of cases, multiple studies have demonstrated freedom from AF leading to significant improvements in symptoms and quality of life $[164,165]$. Results in paroxysmal AF demonstrate that pulmonary vein isolation gives satisfactory symptom control and freedom from AF in around 70 to $80 \%$ patients; however, persistent AF generally requires more complicated procedures involving multiple lesions throughout the left atrium (success rates of 65-75\%) [166]. Several studies have also demonstrated that catheter ablation is more effective than anti-arrhythmic therapy [167-169] at controlling symptoms as well as restoring sinus rhythm, although there is no firm evidence of benefit in terms of mortality or stroke prevention. Most studies have included patients only under the age of 65 , although there have been some small studies suggesting that the procedures can be performed safely in older patients with structurally normal hearts [170].

\section{Conclusion}

To summarise, AF is a heterogeneous condition, with significant differences in its epidemiology, pathogenesis, clinical presentation and management across age groups (shown in Table 6). Older patients are more likely to have an abnormal substrate and present at an advanced stage with atypical symptoms and associated comorbidities. Whilst there have been a few reports of substrate abnormalities in young patients with idiopathic AF thereby implying a causative role, there is not yet conclusive evidence that these do not simply represent AF-induced atrial remodeling. With increasing recognition of rare aetiologies of what was previously deemed to be "idiopathic AF" and the archaic cut-off age to define "lone AF," the term "lone AF" itself is becoming increasingly obsolete. It is all the more pressing therefore to exclude any occult risk factors for AF as this could influence prognosis and management. The important differences between AF in the young and that in the elderly necessitate clearly defined diagnostic and targeted management strategies to relieve symptoms as well as to prevent complications.

\section{Abbreviations}

AF: Atrial fibrillation

APD: Action potential duration

ERP: Effective refractory period. 


\section{Acknowledgment}

The authors are grateful to Professor Andrew Trafford (Cardiovascular Research Group, University of Manchester) for his helpful suggestions.

\section{Funding}

Dr. Sankaranarayanan's research is funded by a grant from the British Heart Foundation (Grant Reference FS/11/15/28693). Dr. Kirkwood's research is funded by a grant from the British Heart Foundation (Grant Reference FS/10/71/28563).

\section{References}

[1] Y. Miyasaka, M. E. Barnes, B. J. Gersh et al., "Secular trends in incidence of atrial fibrillation in Olmsted County, Minnesota, 1980 to 2000, and implications on the projections for future prevalence," Circulation, vol. 114, no. 2, pp. 119-125, 2006.

[2] H. Stefansdottir, T. Aspelund, V. Gudnason et al., "Trends in the incidence and prevalence of atrial fibrillation in Iceland and future projections," Europace, vol. 13, no. 8, pp. 1110-1117, 2011.

[3] H. Rutzen-Lopez, V. Khanna, and M. R. Reynolds, "Atrial fibrillation: epidemiology, prognosis and therapy," Minerva Medica, vol. 102, no. 3, pp. 187-207, 2011.

[4] K. Abusada, S. B. Sharma, R. Jaldai et al., "Epidemiology and management of new-onset atrial fibrillation," American Journal of Managed Care, vol. 10, supplement, pp. S50-S57, 2004.

[5] A. S. Go, E. M. Hylek, K. A. Phillips et al., "Prevalence of diagnosed atrial fibrillation in adults: national implications for rhythm management and stroke prevention: the anticoagulation and risk factors in atrial fibrillation (ATRIA) study," Journal of the American Medical Association, vol. 285, no. 18, pp. 2370-2375, 2001.

[6] E. J. Benjamin, D. Levy, S. M. Vaziri, R. B. D’Agostino, A. J. Belanger, and P. A. Wolf, "Independent risk factors for atrial fibrillation in a population-based cohort. The Framingham Heart Study," Journal of the American Medical Association, vol. 271, no. 11, pp. 840-844, 1994.

[7] D. M. Lloyd-Jones, T. J. Wang, E. P. Leip et al., "Lifetime risk for development of atrial fibrillation: the framingham heart study," Circulation, vol. 110, no. 9, pp. 1042-1046, 2004.

[8] J. Heeringa, D. A. M. Van Der Kuip, A. Hofman et al., "Prevalence, incidence and lifetime risk of atrial fibrillation: the Rotterdam study," European Heart Journal, vol. 27, no. 8, pp. 949-953, 2006.

[9] B. M. Psaty, T. A. Manolio, L. H. Kuller et al., "Incidence of and risk factors for atrial fibrillation in older adults," Circulation, vol. 96, no. 7, pp. 2455-2461, 1997.

[10] F. D. R. Hobbs, D. A. Fitzmaurice, J. Mant et al., "A randomised controlled trial and cost-effectiveness study of systematic screening (targeted and total population screening) versus routine practice for the detection of atrial fibrillation in people aged 65 and over. The SAFE study," Health Technology Assessment, vol. 9, no. 40, pp. 3-5, 2005.

[11] W. Evans and P. Swann, "Lone auricular fibrillation," British Heart Journal, vol. 16, pp. 189-194, 1954.

[12] V. Fuster, L. E. Ryden, D. S. Cannom et al., "ACC/AHA/ESC 2006 Guidelines for the Management of Patients with Atrial
Fibrillation: a report of the American College of Cardiology/American Heart Association Task Force on Practice Guidelines and the European Society of Cardiology Committee for Practice Guidelines (Writing Committee to Revise the 2001 Guidelines for the Management of Patients With Atrial Fibrillation): developed in collaboration with the European Heart Rhythm Association and the Heart Rhythm Society," Circulation, vol. 114, no. 7, pp. e257-e354.

[13] F. N. Brand, R. D. Abbott, W. B. Kannel, and P. A. Wolf, "Characteristics and prognosis of lone atrial fibrillation. 30 year follow-up in the Framingham study," Journal of the American Medical Association, vol. 254, no. 24, pp. 3449-3453, 1985.

[14] A. Jahangir, V. Lee, P. A. Friedman et al., "Long-term progression and outcomes with aging in patients with lone atrial fibrillation: a 30-year follow-up study," Circulation, vol. 115, no. 24, pp. 3050-3056, 2007.

[15] L. Frost, "Lone atrial fibrillation: good, bad, or ugly?" Circulation, vol. 115, no. 24, pp. 3040-3041, 2007.

[16] S. L. Kopecky, B. J. Gersh, M. D. McGoon et al., "Lone atrial fibrillation in elderly persons: a marker for cardiovascular risk," Archives of Internal Medicine, vol. 159, no. 10, pp. 1118-1122, 1999.

[17] B. A. Schoonderwoerd, M. D. Smit, L. Pen, and I. C. Van Gelder, "New risk factors for atrial fibrillation: causes of 'not-so-lone atrial fibrillation"' Europace, vol. 10, no. 6, pp. 668-673, 2008.

[18] D. G. Wyse, "Idiopathic atrial fibrillation: a rose by any other name?" Europace, vol. 14, no. 2, pp. 151-152, 2012.

[19] D. Kozlowski, S. Budrejko, G. Y. H. Lip et al., "Lone atrial fibrillation: what do we know?" Heart, vol. 96, no. 7, pp. 498-503, 2010.

[20] B. Weijs, R. Pisters, R. Nieuwlaat et al., "Idiopathic atrial fibrillation revisited in a large longitudinal clinical cohort," Europace, vol. 14, no. 2, pp. 184-190, 2012.

[21] S. L. Kopecky, B. J. Gersh, and M. D. McGoon, "The natural history of lone atrial fibrillation. A population-based study over three decades," New England Journal of Medicine, vol. 317, no. 11, pp. 669-674, 1987.

[22] C. D. Furberg, B. M. Psaty, T. A. Manolio et al., "Prevalence of atrial fibrillation in elderly subjects (the Cardiovascular Health Study)," American Journal of Cardiology, vol. 74, no. 3, pp. 236-241, 1994.

[23] S. Lévy, M. Maarek, P. Coumel et al., "Characterization of different subsets of atrial fibrillation in general practice in France: the ALFA study," Circulation, vol. 99, no. 23, pp. 3028-3035, 1999.

[24] L. Wolff, "Familial auricular fibrillation," The New England Journal of Medicine, vol. 229, pp. 396-398, 1943.

[25] D. Darbar, K. J. Herron, J. D. Ballew et al., "Familial atrial fibrillation is a genetically heterogeneous disorder," Journal of the American College of Cardiology, vol. 41, no. 12, pp. 2185-2192, 2003.

[26] P. T. Ellinor, D. M. Yoerger, J. N. Ruskin, and C. A. MacRae, "Familial aggregation in lone atrial fibrillation," Human Genetics, vol. 118, no. 2, pp. 179-184, 2005.

[27] C. S. Fox, H. Parise, R. B. D’Agostino et al., "Parental atrial fibrillation as a risk factor for atrial fibrillation in offspring," Journal of the American Medical Association, vol. 291, no. 23, pp. 2851-2855, 2004.

[28] R. Brugada, T. Tapscott, G. Z. Czernuszewicz et al., "Identification of a genetic locus for familial atrial fibrillation," New England Journal of Medicine, vol. 336, no. 13, pp. 905-911, 1997. 
[29] M. F. Sinner, P. T. Ellinor, T. Meitinger, E. J. Benjamin, and S. Kääb, "Genome-wide association studies of atrial fibrillation: past, present, and future," Cardiovascular Research, vol. 89, no. 4, pp. 701-709, 2011.

[30] Y. H. Chen, S. J. Xu, S. Bendahhou et al., "KCNQ1 gain-offunction mutation in familial atrial fibrillation," Science, vol. 299, no. 5604, pp. 251-254, 2003.

[31] Y. Yang, M. Xia, Q. Jin et al., "Identification of a KCNE2 gainof-function mutation in patients with familial atrial fibrillation," American Journal of Human Genetics, vol. 75, no. 5, pp. 899-905, 2004.

[32] M. Xia, Q. Jin, S. Bendahhou et al., "A Kir2.1 gain-of-function mutation underlies familial atrial fibrillation," Biochemical and Biophysical Research Communications, vol. 332, no. 4, pp. 1012-1019, 2005.

[33] T. M. Olson, A. E. Alekseev, X. K. Liu et al., "Kv1.5 channelopathy due to KCNA5 loss-of-function mutation causes human atrial fibrillation," Human Molecular Genetics, vol. 15, no. 14, pp. 2185-2191, 2006.

[34] L. Y. Chen, J. D. Ballew, K. J. Herron, R. J. Rodeheffer, and T. M. Olson, "A common polymorphism in SCN5A is associated with lone atrial fibrillation," Clinical Pharmacology and Therapeutics, vol. 81, no. 1, pp. 35-41, 2007.

[35] M. H. Gollob, D. L. Jones, A. D. Krahn et al., "Somatic mutations in the connexin 40 gene (GJA5) in atrial fibrillation," New England Journal of Medicine, vol. 354, no. 25, pp. 2677-2688, 2006.

[36] T. M. Olson, A. E. Alekseev, C. Moreau et al., "KATP channel mutation confers risk for vein of Marshall adrenergic atrial fibrillation," Nature Clinical Practice Cardiovascular Medicine, vol. 4, no. 2, pp. 110-116, 2007.

[37] P. O. Ettinger, C. F. Wu, C. De La Cruz Jr., A. B. Weisse, S. S. Ahmed, and T. J. Regan, "Arrhythmias and the 'holiday heart': alcohol associated cardiac rhythm disorders," American Heart Journal, vol. 95, no. 5, pp. 555-562, 1978.

[38] C. E. B. Balbão, A. A. V. de Paola, and G. Fenelon, "Effects of alcohol on atrial fibrillation: myths and truths," Therapeutic Advances in Cardiovascular Disease, vol. 3, no. 1, pp. 53-63, 2009.

[39] S. R. Lowenstein, P. A. Gabow, and J. Cramer, "The role of alcohol in new-onset atrial fibrillation," Archives of Internal Medicine, vol. 143, no. 10, pp. 1882-1885, 1983.

[40] K. J. Mukamal, B. M. Psaty, P. M. Rautaharju et al., "Alcohol consumption and risk and prognosis of atrial fibrillation among older adults: the Cardiovascular Health Study," American Heart Journal, vol. 153, no. 2, pp. 260-266, 2007.

[41] G. M. Marcus, L. M. Smith, D. Whiteman et al., "Alcohol intake is significantly associated with atrial flutter in patients under 60 years of age and a shorter right atrial effective refractory period," Pacing and Clinical Electrophysiology, vol. 31, no. 3, pp. 266-272, 2008.

[42] N. Wanahita, F. H. Messerli, S. Bangalore, A. S. Gami, V. K. Somers, and J. S. Steinberg, "Atrial fibrillation and obesity-results of a meta-analysis," American Heart Journal, vol. 155, no. 2, pp. 310-315, 2008.

[43] T. J. Wang, H. Parise, D. Levy et al., "Obesity and the risk of new-onset atrial fibrillation," Journal of the American Medical Association, vol. 292, no. 20, pp. 2471-2477, 2004.

[44] C. S. Ku, S. L. Lin, D. J. Wang, S. K. Chang, and W. J. Lee, "Left ventricular filling in young normotensive obese adults," American Journal of Cardiology, vol. 73, no. 8, pp. 613-615, 1994.
[45] L. Frost, L. J. Hune, and P. Vestergaard, “Overweight and obesity as risk factors for atrial fibrillation or flutter: the Danish Diet, Cancer, and Health Study," American Journal of Medicine, vol. 118, no. 5, pp. 489-495, 2005.

[46] S. Dublin, B. French, N. L. Glazer et al., "Risk of new-onset atrial fibrillation in relation to body mass index," Archives of Internal Medicine, vol. 166, no. 21, pp. 2322-2328, 2006.

[47] A. S. Gami, D. O. Hodge, R. M. Herges et al., "Obstructive sleep apnea, obesity, and the risk of incident atrial fibrillation," Journal of the American College of Cardiology, vol. 49, no. 5, pp. 565-571, 2007.

[48] L. Mont, D. Tamborero, R. Elosua et al., "Physical activity, height, and left atrial size are independent risk factors for lone atrial fibrillation in middle-aged healthy individualsEuropace," vol. 10, no. 1, pp. 15-20, 2008.

[49] F. Furlanello, A. Bertoldi, M. Dallago et al., "Atrial fibrillation in elite athletes," Journal of Cardiovascular Electrophysiology, vol. 9, no. 8, supplement, pp. S63-S68, 1998.

[50] L. Molina, L. Mont, J. Marrugat et al., "Long-term endurance sport practice increases the incidence of lone atrial fibrillation in men: a follow-up study," Europace, vol. 10, no. 5, pp. 618-623, 2008.

[51] L. Mont, A. Sambola, J. Brugada et al., "Long-lasting sport practice and lone atrial fibrillation," European Heart Journal, vol. 23, no. 6, pp. 477-482, 2002.

[52] R. Elosua, A. Arquer, L. Mont et al., "Sport practice and the risk of lone atrial fibrillation: a case-control study," International Journal of Cardiology, vol. 108, no. 3, pp. 332-337, 2006.

[53] J. Karjalainen, U. M. Kujala, J. Kaprio, S. Sarna, and M. Viitasalo, "Lone atrial fibrillation in vigorously exercising middle aged men: case-control study," British Medical Journal, vol. 316, no. 7147, pp. 1784-1785, 1998.

[54] J. Abdulla and J. R. Nielsen, "Is the risk of atrial fibrillation higher in athletes than in the general population? A systematic review and meta-analysis," Europace, vol. 11, no. 9, pp. 1156-1159, 2009.

[55] J. D. Edwards and R. G. Wilkins, "Atrial fibrillation precipitated by acute hypovolaemia," British Medical Journal, vol. 294, no. 6567, pp. 283-284, 1987.

[56] I. Olivotto, F. Cecchi, S. A. Casey, A. Dolara, J. H. Traverse, and B. J. Maron, "Impact of atrial fibrillation on the clinical course of hypertrophic cardiomyopathy," Circulation, vol. 104, no. 21, pp. 2517-2524, 2001.

[57] J. Bouchardy, J. Therrien, L. Pilote et al., "Atrial arrhythmias in adults with congenital heart disease," Circulation, vol. 120, no. 17, pp. 1679-1686, 2009.

[58] A. V. Mattioli, S. Bonatti, M. Zennaro, and G. Mattioli, "The relationship between personality, socio-economic factors, acute life stress and the development, spontaneous conversion and recurrences of acute lone atrial fibrillation," Europace, vol. 7, no. 3, pp. 211-220, 2005.

[59] E. D. Eaker, L. M. Sullivan, M. Kelly-Hayes, R. B. D’Agostino, and E. J. Benjamin, "Anger and hostility predict the development of atrial fibrillation in men in the framingham offspring study," Circulation, vol. 109, no. 10, pp. 1267-1271, 2004.

[60] A. V. Mattioli, S. Bonatti, M. Zennaro, R. Melotti, and G. Mattioli, "Effect of coffee consumption, lifestyle and acute life stress in the development of acute lone atrial fibrillation," Journal of Cardiovascular Medicine, vol. 9, no. 8, pp. 794-798, 2008. 
[61] A. Rashid, M. Hines, B. J. Scherlag, W. S. Yamanashi, and W. Lovallo, "The effects of caffeine on the inducibility of atrial fibrillation," Journal of Electrocardiology, vol. 39, no. 4, pp. 421-425, 2006.

[62] L. Frost and P. Vestergaard, "Caffeine and risk of atrial fibrillation or flutter: the Danish diet, cancer, and health study," American Journal of Clinical Nutrition, vol. 81, no. 3, pp. 578-582, 2005.

[63] A. Goette, U. Lendeckel, A. Kuchenbecker et al., "Cigarette smoking induces atrial fibrosis in humans via nicotine," Heart, vol. 93, no. 9, pp. 1056-1063, 2007.

[64] K. M. Ryder and E. J. Benjamin, "Epidemiology and significance of atrial fibrillation," American Journal of Cardiology, vol. 84, no. 9, pp. R131-R138, 1999.

[65] R. B. Schnabel, L. M. Sullivan, D. Levy et al., "Development of a risk score for atrial fibrillation (Framingham Heart Study): a community-based cohort study," The Lancet, vol. 373, no. 9665, pp. 739-745, 2009.

[66] M. A. Rosenberg, J. S. Gottdiener, S. R. Heckbert et al., "Echocardiographic diastolic parameters and risk of atrial fibrillation: the Cardiovascular Health Study," European Heart Journal, vol. 33, no. 7, pp. 904-912, 2012.

[67] K. K. Patton, P. T. Ellinor, S. R. Heckbert et al., "N-Terminal pro-b-type natriuretic peptide is a major predictor of the development of atrial fibrillation: the cardiovascular health study," Circulation, vol. 120, no. 18, pp. 1768-1774, 2009.

[68] T. Agner, T. Almdal, B. Thorsteinsson, and E. Agner, "A reevaluation of atrial fibrillation in thyrotoxicosis," Danish medical bulletin, vol. 31, no. 2, pp. 157-159, 1984.

[69] M. Haissaguerre, P. Jais, D. C. Shah et al., "Spontaneous initiation of atrial fibrillation by ectopic beats originating in the pulmonary veins1998," The New England Journal of Medicine, vol. 339, no. 10, pp. 659-666.

[70] P. Jaïs, M. Hocini, L. Macle et al., "Distinctive electrophysiological properties of pulmonary veins in patients with atrial fibrillation," Circulation, vol. 106, no. 19, pp. 2479-2485, 2002.

[71] A. Frustaci, C. Chimenti, F. Bellocci, E. Morgante, M. A. Russo, and A. Maseri, "Histological substrate of atrial biopsies in patients with lone atrial fibrillation," Circulation, vol. 96, no. 4, pp. 1180-1184, 1997.

[72] A. Frustaci, M. Caldarulo, A. Buffon, F. Bellocci, R. Fenici, and D. Melina, "Cardiac biopsy in patients with 'primary' atrial fibrillation; Histologic evidence of occult myocardial diseases," Chest, vol. 100, no. 2, pp. 303-306, 1991.

[73] M. K. Stiles, B. John, C. X. Wong et al., "Paroxysmal lone atrial fibrillation is associated with an abnormal atrial substrate: characterizing the 'second factor," Journal of the American College of Cardiology, vol. 53, no. 14, pp. 1182-1191, 2009.

[74] F. Holmqvist, M. S. Olesen, A. Tveit et al., "Abnormal atrial activation in young patients with lone atrial fibrillation," Europace, vol. 13, no. 2, pp. 188-192, 2011.

[75] P. Korantzopoulos, T. Kolettis, K. Siogas, and J. Goudevenos, "Atrial fibrillation and electrical remodeling: the potential role of inflammation and oxidative stress," Medical Science Monitor, vol. 9, no. 9, pp. RA225-RA229, 2003.

[76] C. J. Garratt, M. Duytschaever, M. Killian, R. Dorland, F. Mast, and M. A. Allessie, "Repetitive electrical remodeling by paroxysms of atrial fibrillation in the goat: no cumulative effect on inducibility or stability of atrial fibrillation," Journal of Cardiovascular Electrophysiology, vol. 10, no. 8, pp. 1101-1108, 1999.
[77] D. M. Todd, S. P. Fynn, A. P. Walden, W. J. Hobbs, S. Arya, and C. J. Garratt, "Repetitive 4-week periods of atrial electrical remodeling promote stability of atrial fibrillation: time course of a second factor involved in the self-perpetuation of atrial fibrillation," Circulation, vol. 109, no. 11, pp. 1434-1439, 2004.

[78] T. T. Issac, H. Dokainish, and N. M. Lakkis, "Role of inflammation in initiation and perpetuation of atrial fibrillation: a systematic review of the published data," Journal of the American College of Cardiology, vol. 50, no. 21, pp. 2021-2028, 2007.

[79] D. S. G. Conway, P. Buggins, E. Hughes, and G. Y. H. Lip, "Prognostic significance of raised plasma levels of interleukin6 and C-reactive protein in atrial fibrillation," American Heart Journal, vol. 148, no. 3, pp. 462-466, 2004.

[80] C. J. Boos and G. Y. H. Lip, "C-reactive protein and lone atrial fibrillation: potential confounders," American Journal of Cardiology, vol. 98, no. 7, pp. 991-992, 2006.

[81] M. J. Mihm, F. Yu, C. A. Carnes et al., "Impaired myofibrillar energetics and oxidative injury during human atrial fibrillation," Circulation, vol. 104, no. 2, pp. 174-180, 2001.

[82] P. T. Ellinor, A. Low, K. K. Patton, M. A. Shea, and C. A. MacRae, "C-reactive protein in lone atrial fibrillation," American Journal of Cardiology, vol. 97, no. 9, pp. 1346-1350, 2006.

[83] R. J. Aviles, D. O. Martin, C. pperson-Hansen et al., "Inflammation as a risk factor for atrial fibrillation," Circulation, vol. 108, no. 24, pp. 3006-3010, 2003.

[84] E. Hatzinikolaou-Kotsakou, D. Tziakas, A. Hotidis et al., "Relation of C-reactive protein to the first onset and the recurrence rate in lone atrial fibrillation," American Journal of Cardiology, vol. 97, no. 5, pp. 659-661, 2006.

[85] E. I. Skalidis, M. I. Hamilos, I. K. Karalis, G. Chlouverakis, G. E. Kochiadakis, and P. E. Vardas, "Isolated atrial microvascular dysfunction in patients with lone recurrent atrial fibrillation," Journal of the American College of Cardiology, vol. 51, no. 21, pp. 2053-2057, 2008.

[86] P. Jais, J. T. Peng, D. C. Shah et al., "Left ventricular diastolic dysfunction in patients with so-called lone atrial fibrillation," Journal of Cardiovascular Electrophysiology, vol. 11, no. 6, pp. 623-625, 2000.

[87] K. C. Roberts-Thomson, P. M. Kistler, P. Sanders et al., "Fractionated atrial electrograms during sinus rhythm: relationship to age, voltage, and conduction velocity," Heart Rhythm, vol. 6, no. 5, pp. 587-591, 2009.

[88] N. Ono, H. Hayashi, A. Kawase et al., "Spontaneous atrial fibrillation initiated by triggered activity near the pulmonary veins in aged rats subjected to glycolytic inhibition," American Journal of Physiology. Heart and Circulatory Physiology, vol. 292, no. 1, pp. H639-H648, 2007.

[89] O. A. Centurión, S. Isomoto, A. Shimizu et al., "The effects of aging on atrial endocardial electrograms in patients with paroxysmal atrial fibrillation," Clinical Cardiology, vol. 26, no. 9, pp. 435-438, 2003.

[90] W. Wongcharoen, Y. C. Chen, Y. J. Chen et al., "Aging increases pulmonary veins arrhythmogenesis and susceptibility to calcium regulation agents," Heart Rhythm, vol. 4, no. 10, pp. 1338-1349, 2007.

[91] W. Wongcharoen, Y. C. Chen, Y. J. Chen, C. I. Lin, and S. A. Chen, "Effects of aging and ouabain on left atrial arrhythmogenicity," Journal of Cardiovascular Electrophysiology, vol. 18, no. 5, pp. 526-531, 2007.

[92] E. P. Anyukhovsky, E. A. Sosunov, A. Plotnikov et al., "Cellular electrophysiologic properties of old canine atria provide a 
substrate for arrhythmogenesis," Cardiovascular Research, vol. 54, no. 2, pp. 462-469, 2002.

[93] E. P. Anyukhovsky, E. A. Sosunov, P. Chandra et al., "Ageassociated changes in electrophysiologic remodeling: a potential contributor to initiation of atrial fibrillation," Cardiovascular Research, vol. 66, no. 2, pp. 353-363, 2005.

[94] K. Sakabe, N. Fukuda, T. Nada et al., "Age-related changes in the electrophysiologic properties of the atrium in patients with no history of atrial fibrillation," Japanese Heart Journal, vol. 44, no. 3, pp. 385-393, 2003.

[95] K. Sakabe, N. Fukuda, T. Soeki et al., "Relation of age and sex to atrial electrophysiological properties in patients with no history of atrial fibrillation," Pacing and Clinical Electrophysiology, vol. 26, no. 5, pp. 1238-1244, 2003.

[96] B. Brembilla-Perrot, G. Burger, D. Beurrier et al., "Influence of age on atrial fibrillation inducibility," Pacing and Clinical Electrophysiology, vol. 27, no. 3, pp. 287-292, 2004.

[97] L. Hove-Madsen, A. Llach, A. Bayes-Genís et al., "Atrial fibrillation is associated with increased spontaneous calcium release from the sarcoplasmic reticulum in human atrial myocytes," Circulation, vol. 110, no. 11, pp. 1358-1363, 2004.

[98] J. A. Vest, X. H. T. Wehrens, S. R. Reiken et al., "Defective cardiac ryanodine receptor regulation during atrial fibrillation," Circulation, vol. 111, no. 16, pp. 2025-2032, 2005.

[99] A. El-Armouche, P. Boknik, T. Eschenhagen et al., "Molecular determinants of altered $\mathrm{Ca}^{2+}$ handling in human chronic atrial fibrillation," Circulation, vol. 114, no. 7, pp. 670-680, 2006.

[100] P. M. Kistler, P. Sanders, S. P. Fynn et al., "Electrophysiologic and electroanatomic changes in the human atrium associated with age," Journal of the American College of Cardiology, vol. 44, no. 1, pp. 109-116, 2004.

[101] L. Brorson and S. B. Olsson, "Right atrial monophasic action potential in healthy males. Studies during spontaneous sinus rhythm and atrial pacing," Acta Medica Scandinavica, vol. 199, no. 6, pp. 433-446, 1976.

[102] N. Toda, "Age-related changes in the transmembrane potential of isolated rabbit sino-atrial nodes and atria," Cardiovascular Research, vol. 14, no. 1, pp. 58-63, 1980.

[103] N. Su, J. Duan, M. P. Moffat, and N. Narayanan, "Age related changes in electrophysiological responses to muscarinic receptor stimulation in rat myocardium," Canadian Journal of Physiology and Pharmacology, vol. 73, no. 10, pp. 1430-1436, 1995.

[104] W. Dun and P. A. Boyden, "Aged atria: electrical remodeling conducive to atrial fibrillation," Journal of Interventional Cardiac Electrophysiology, vol. 25, no. 1, pp. 9-18, 2009.

[105] A. Michelucci, L. Padeletti, and G. A. Fradella, "Ageing and atrial electrophysiologic properties in man," International Journal of Cardiology, vol. 5, no. 1, pp. 75-81, 1984.

[106] C. Huang, W. Ding, L. Li, and D. Zhao, "Differences in the agingassociated trends of the monophasic action potential duration and effective refractory period of the right and left atria of the rat," Circulation Journal, vol. 70, no. 3, pp. 352-357, 2006.

[107] P. Kojodjojo, P. Kanagaratnam, V. Markides, D. W. Davies, and N. Peters, "Age-related changes in human left and right atrial conduction," Journal of Cardiovascular Electrophysiology, vol. 17, no. 2, pp. 120-127, 2006.

[108] S. Baba, W. Dun, M. Hirose, and P. A. Boyden, "Sodium current function in adult and aged canine atrial cells," American Journal of Physiology. Heart and Circulatory Physiology, vol. 291, no. 2, pp. H756-H761, 2006.
[109] W. Dun, T. Yagi, M. R. Rosen, and P. A. Boyden, "Calcium and potassium currents in cells from adult and aged canine right atria," Cardiovascular Research, vol. 58, no. 3, pp. 526-534, 2003.

[110] C. C. Wu, M. J. Su, J. F. Chi, M. H. Wu, and Y. T. Lee, "Comparison of aging and hypercholesterolemic effects on the sodium inward currents in cardiac myocytes," Life Sciences, vol. 61, no. 16, pp. 1539-1551, 1997.

[111] H. Hayashi, C. Wang, Y. Miyauchi et al., "Aging-related increase to inducible atrial fibrillation in the rat model," Journal of Cardiovascular Electrophysiology, vol. 13, no. 8, pp. 801-808, 2002.

[112] S. Sossalla, B. Kallmeyer, S. Wagner et al., "Altered $\mathrm{Na}^{+}$currents in atrial fibrillation. effects of ranolazine on arrhythmias and contractility in human atrial myocardium," Journal of the American College of Cardiology, vol. 55, no. 21, pp. 2330-2342, 2010.

[113] R. Gaspo, R. F. Bosch, E. Bou-Abboud, and S. Nattel, "Tachycardia-induced changes in $\mathrm{Na}^{+}$current in a chronic dog model of atrial fibrillation," Circulation Research, vol. 81, no. 6, pp. 1045-1052, 1997.

[114] P. Kanagaratnam, A. Cherian, R. D. L. Stanbridge, B. Glenville, N. J. Severs, and N. S. Peters, "Relationship between connexins and atrial activation during human atrial fibrillation," Journal of Cardiovascular Electrophysiology, vol. 15, no. 2, pp. 206-213, 2004.

[115] S. A. Jones, M. K. Lancaster, and M. R. Boyett, "Ageing-related changes of connexins and conduction within the sinoatrial node," Journal of Physiology, vol. 560, no. 2, pp. 429-437, 2004.

[116] T. Koura, M. Hara, S. Takeuchi et al., "Anisotropic conduction properties in canine atria analyzed by high-resolution optical mapping: preferential direction of conduction block changes from longitudinal to transverse with increasing age," Circulation, vol. 105, no. 17, pp. 2092-2098, 2002.

[117] M. S. Spach, J. F. Heidlage, P. C. Dolber, and R. C. Barr, "Mechanism of origin of conduction disturbances in aging human atrial bundles: experimental and model study," Heart Rhythm, vol. 4, no. 2, pp. 175-185, 2007.

[118] C. Chimenti, M. A. Russo, A. Carpi, and A. Frustaci, "Histological substrate of human atrial fibrillation," Biomedicine and Pharmacotherapy, vol. 64, no. 3, pp. 177-183, 2010.

[119] S. Verheule, E. Tuyls, A. Van Hunnik, M. Kuiper, U. Schotten, and M. Allessie, "Fibrillatory conduction in the atrial free walls of goats in persistent and permanent atrial fibrillation," Circulation: Arrhythmia and Electrophysiology, vol. 3, no. 6, pp. 590-599, 2010.

[120] M. S. Spach and P. C. Dolber, "Relating extracellular potentials and their derivatives to anisotropic propagation at a microscopic level in human cardiac muscle: evidence for electrical uncoupling of side-to-side fiber connections with increasing age," Circulation Research, vol. 58, no. 3, pp. 356-371, 1986.

[121] P. H. Lin, S. H. Lee, C. P. Su, and Y. H. Wei, "Oxidative damage to mitochondrial DNA in atrial muscle of patients with atrial fibrillation," Free Radical Biology and Medicine, vol. 35, no. 10, pp. 1310-1318, 2003.

[122] N. H. Pan, H. M. Tsao, N. Chang, Y. J. Chen, and S. A. Chen, "Aging dilates atrium and pulmonary veins: implications for the genesis of atrial fibrillation," Chest, vol. 133, no. 1, pp. 190-196, 2008.

[123] S. A. Nazir and M. J. Lab, "Mechanoelectric feedback and atrial arrhythmias," Cardiovascular Research, vol. 32, no. 1, pp. 52-61, 1996. 
[124] A. Ruigómez, S. Johansson, M. A. Wallander, and L. A. García Rodríguez, "Predictors and prognosis of paroxysmal atrial fibrillation in general practice in the UK," BMC Cardiovascular Disorders, vol. 5, article no. 20, 2005.

[125] C. R. Kerr, K. H. Humphries, M. Talajic et al., "Progression to chronic atrial fibrillation after the initial diagnosis of paroxysmal atrial fibrillation: results from the Canadian Registry of Atrial Fibrillation," American Heart Journal, vol. 149, no. 3, pp. 489-496, 2005.

[126] S. A. Lopez, F. Formiga, X. Bosch et al., "Prevalence of atrial fibrillation and related factors in hospitalized old patients: ESFINGE study," Medicina Clínica, vol. 138, no. 6, pp. 231-237, 2012.

[127] C. B. de Vos, R. Pisters, R. Nieuwlaat et al., "Progression from paroxysmal to persistent atrial fibrillation. clinical correlates and prognosis," Journal of the American College of Cardiology, vol. 55, no. 8, pp. 725-731, 2010.

[128] C. Kerr, J. Boone, S. Connolly et al., "Follow-up of atrial fibrillation: the initial experience of the Canadian Registry of Atrial Fibrillation," European Heart Journal, vol. 17, no. 7, supplement, pp. 48-51, 1996.

[129] N. D. Brunetti, L. De Gennaro, P. L. Pellegrino, G. Dellegrottaglie, G. Antonelli, and M. Di Biase, "Atrial fibrillation with symptoms other than palpitations: incremental diagnostic sensitivity with at-home tele-cardiology assessment for emergency medical service," European Journal of Preventive Cardiology, vol. 19, no. 3, pp. 306-313, 2011.

[130] U. Lotze, J. Liebetrau, I. Malsch et al., "Medical treatment of patients with atrial fibrillation aged over 80 years in daily clinical practice: influence of age and CHADS2 score," Archives of Gerontology and Geriatrics, vol. 50, no. 1, pp. 36-41, 2010.

[131] S. Kralev, K. Schneider, S. Lang et al., "Incidence and severity of coronary artery disease in patients with atrial fibrillation undergoing first-time coronary angiography," PLoS One, vol. 6, no. 9, Article ID e24964, 2011.

[132] J. Liao, Z. Khalid, C. Scallan, C. Morillo, and M. O’Donnell, "Noninvasive cardiac monitoring for detecting paroxysmal atrial fibrillation or flutter after acute ischemic stroke: a systematic review," Stroke, vol. 38, no. 11, pp. 2935-2940, 2007.

[133] K. Lakshminarayan, C. A. Solid, A. J. Collins, D. C. Anderson, and C. A. Herzog, "Atrial fibrillation and stroke in the general medicare population: a 10-year perspective (1992 to 2002)," Stroke, vol. 37, no. 8, pp. 1969-1974, 2006.

[134] P. A. Wolf, R. D. Abbott, and W. B. Kannel, "Atrial fibrillation as an independent risk factor for stroke: the Framingham Study," Stroke, vol. 22, no. 8, pp. 983-988, 1991.

[135] R. G. Hart, O. Benavente, R. McBride, and L. A. Pearce, "Antithrombotic therapy to prevent stroke in patients with atrial fibrillation: a meta-analysis," Annals of Internal Medicine, vol. 131, no. 7, pp. 492-501, 1999.

[136] D. N. Salem, P. D. Stein, A. Al-Ahmad et al., "Antithrombotic therapy in valvular heart disease-native and prosthetic: the 7th ACCP Conference on Antithrombotic and Thrombolytic Therapy," Chest, vol. 126, no. 3, supplement, pp. 457S-482S, 2004.

[137] B. F. Gage, A. D. Waterman, W. Shannon, M. Boechler, M. W. Rich, and M. J. Radford, "Validation of clinical classification schemes for predicting stroke: results from the National Registry of Atrial Fibrillation," Journal of the American Medical Association, vol. 285, no. 22, pp. 2864-2870, 2001.

[138] M. Hughes and G. Y. H. Lip, "Stroke and thromboembolism in atrial fibrillation: a systematic review of stroke risk factors, risk stratification schema and cost effectiveness data," Thrombosis and Haemostasis, vol. 99, no. 2, pp. 295-304, 2008.

[139] Stroke in AF Working Group, "Independent predictors of stroke in patients with atrial fibrillation: a systematic review," Neurology, vol. 69, no. 6, pp. 546-554, 2007.

[140] G. Y. H. Lip, R. Nieuwlaat, R. Pisters, D. A. Lane, and H. J. G. M. Crijns, "Refining clinical risk stratification for predicting stroke and thromboembolism in atrial fibrillation using a novel risk factor-based approach: the Euro Heart Survey on atrial fibrillation," Chest, vol. 137, no. 2, pp. 263-272, 2010.

[141] D. E. Singer, Y. Chang, M. C. Fang et al., "The net clinical benefit of warfarin anticoagulation in atrial fibrillation," Annals of Internal Medicine, vol. 151, no. 5, pp. 297-305, 2009.

[142] A. S. Go, E. M. Hylek, L. H. Borowsky, K. A. Phillips, J. V. Selby, and D. E. Singer, "Warfarin use among ambulatory patients with nonvalvular atrial fibrillation: the anticoagulation and risk factors in atrial fibrillation (ATRIA) study," Annals of Internal Medicine, vol. 131, no. 12, pp. 927-934, 1999.

[143] D. Pugh, J. Pugh, and G. E. Mead, "Attitudes of physicians regarding anticoagulation for atrial fibrillation: a systematic review," Age Ageing, vol. 40, no. 6, pp. 675-683, 2011.

[144] R. Marinigh, G. Y. H. Lip, N. Fiotti, C. Giansante, and D. A. Lane, "Age as a risk factor for stroke in atrial fibrillation patients: implications for thromboprophylaxis," Journal of the American College of Cardiology, vol. 56, no. 11, pp. 827-837, 2010.

[145] M. C. Fang, A. S. Go, Y. Chang et al., "Death and disability from warfarin-associated intracranial and extracranial hemorrhages," American Journal of Medicine, vol. 120, no. 8, pp. 700-705, 2007.

[146] E. M. Hylek, C. Evans-Molina, C. Shea, L. E. Henault, and S. Regan, "Major hemorrhage and tolerability of warfarin in the first year of therapy among elderly patients with atrial fibrillation," Circulation, vol. 115, no. 21, pp. 2689-2696, 2007.

[147] M. Man-Son-Hing, G. Nichol, A. Lau, and A. Laupacis, "Choosing antithrombotic therapy for elderly patients with atrial fibrillation who are at risk for falls," Archives of Internal Medicine, vol. 159, no. 7, pp. 677-685, 1999.

[148] R. Pisters, D. A. Lane, R. Nieuwlaat, C. B. De Vos, H. J. G. M. Crijns, and G. Y. H. Lip, "A novel user-friendly score (HASBLED) to assess 1-year risk of major bleeding in patients with atrial fibrillation: the Euro heart survey," Chest, vol. 138, no. 5, pp. 1093-1100, 2010.

[149] D. J. Stott, R. I. Dewar, C. J. Garratt et al., "RCPE UK consensus conference on 'Approaching the comprehensive management of atrial fibrillation: evolution or revolution?"' The Journal of the Royal College of Physicians of Edinburgh, vol. 42, supplement 18, pp. 3-4.

[150] S. J. Connolly, M. D. Ezekowitz, S. Yusuf et al., "Dabigatran versus warfarin in patients with atrial fibrillation," The New England Journal of Medicine, vol. 361, no. 12, pp. 1139-1151, 2009.

[151] J. W. Eikelboom, L. Wallentin, S. J. Connolly et al., "Risk of bleeding with 2 doses of dabigatran compared with warfarin in older and younger patients with atrial fibrillation: an analysis of the randomized evaluation of long-term anticoagulant therapy (RE-LY) Trial," Circulation, vol. 123, no. 21, pp. 2363-2372, 2011.

[152] M. R. Patel, K. W. Mahaffey, J. Garg et al., "Rivaroxaban versus warfarin in nonvalvular atrial fibrillation," The New England Journal of Medicine, vol. 365, no. 10, pp. 883-891, 2011. 
[153] C. B. Granger, J. H. Alexander, J. J. McMurray et al., "Apixaban versus warfarin in patients with atrial fibrillation," The New England Journal of Medicine, vol. 365, no. 11, pp. 981-992, 2011.

[154] D. G. Wyse, "Rate control vs rhythm control strategies in atrial fibrillation," Progress in Cardiovascular Diseases, vol. 48, no. 2, pp. 125-138, 2005.

[155] I. C. Van Gelder, H. F. Groenveld, H. J. G. M. Crijns et al., "Lenient versus strict rate control in patients with atrial fibrillation," New England Journal of Medicine, vol. 362, no. 15, pp. 1363-1373, 2010.

[156] I. C. Van Gelder, D. G. Wyse, M. L. Chandler et al., "Does intensity of rate-control influence outcome in atrial fibrillation? An analysis of pooled data from the RACE and AFFIRM studies," Europace, vol. 8, no. 11, pp. 935-942, 2006.

[157] M. Brignole, G. L. Botto, L. Mont et al., "Predictors of clinical efficacy of 'Ablate and Pace' therapy in patients with permanent atrial fibrillation," Heart, vol. 98, no. 4, pp. 297-302, 2012.

[158] A. N. Ganesan, A. G. Brooks, K. C. Roberts-Thomson et al., "Role of AV nodal ablation in cardiac resynchronization in patients with coexistent atrial fibrillation and heart failure a systematic review," Journal of the American College of Cardiology, vol. 59, no. 8, pp. 719-726, 2012.

[159] A. E. Epstein, "Relationships between snus rhythm, treatment, and survival in the Atrial Fibrillation Follow-Up Investigation of Rhythm Management (AFFIRM) study," Circulation, vol. 109, no. 12, pp. 1509-1513, 2004.

[160] A. J. Camm, P. Kirchhof, G. Y. Lip et al., "Guidelines for the management of atrial fibrillation: the Task Force for the Management of Atrial Fibrillation of the European Society of Cardiology (ESC)," European Heart Journal, vol. 31, no. 19, pp. 2369-2429, 2010.

[161] C. Lafuente-Lafuente, S. Mouly, M. A. Longas-Tejero, and J. F. Bergmann, "Antiarrhythmics for maintaining sinus rhythm after cardioversion of atrial fibrillation," Cochrane Database of Systematic Reviews, no. 4, Article ID CD005049, 2007.

[162] J. Y. Le Heuzey, G. M. De Ferrari, D. Radzik, M. Santini, J. Zhu, and J. M. Davy, "A short-term, randomized, doubleblind, parallel-group study to evaluate the efficacy and safety of dronedarone versus amiodarone in patients with persistent atrial fibrillation: the dionysos study," Journal of Cardiovascular Electrophysiology, vol. 21, no. 6, pp. 597-605, 2010.

[163] S. J. Connolly, H. J. G. M. Crijns, C. Torp-Pedersen et al., "Analysis of stroke in ATHENA: a placebo-controlled, doubleblind, parallel-arm trial to assess the efficacy of dronedarone $400 \mathrm{mg}$ bid for the prevention of cardiovascular hospitalization or death from any cause in patients with atrial fibrillation/atrial flutter," Circulation, vol. 120, no. 13, pp. 1174-1180, 2009.

[164] M. R. Reynolds, J. Walczak, S. A. White, D. J. Cohen, and D. J. Wilber, "Improvements in symptoms and quality of life in patients with paroxysmal atrial fibrillation treated with radiofrequency catheter ablation versus antiarrhythmic drugs," Circulation: Cardiovascular Quality and Outcomes, vol. 3, no. 6, pp. 615-623, 2010.

[165] J. P. Piccini, R. D. Lopes, M. H. Kong, V. Hasselblad, K. Jackson, and S. M. Al-Khatib, "Pulmonary vein isolation for the maintenance of sinus rhythm in patients with atrial fibrillation a meta-analysis of randomized, controlled trials," Circulation: Arrhythmia and Electrophysiology, vol. 2, no. 6, pp. 626-633, 2009.

[166] R. Cappato, H. Calkins, S. A. Chen et al., "Updated worldwide survey on the methods, efficacy, and safety of catheter ablation for human atrial fibrillation," Circulation: Arrhythmia and Electrophysiology, vol. 3, no. 1, pp. 32-38, 2010.

[167] A. Noheria, A. Kumar, J. V. Wylie, and M. E. Josephson, "Catheter ablation vs antiarrhythmic drug therapy for atrial fibrillation: a systematic review," Archives of Internal Medicine, vol. 168, no. 6, pp. 581-586, 2008.

[168] P. Jaï, B. Cauchemez, L. Macle et al., "Catheter ablation versus antiarrhythmic drugs for atrial fibrillation: the A4 study," Circulation, vol. 118, no. 24, pp. 2498-2505, 2008.

[169] H. Calkins, M. R. Reynolds, P. Spector et al., "Treatment of atrial fibrillation with antiarrhythmic drugs or radiofrequency ablation: two systematic literature reviews and meta-analyses," Circulation: Arrhythmia and Electrophysiology, vol. 2, no. 4, pp. 349-361, 2009.

[170] L. M. Haegeli, F. Duru, E. E. Lockwood et al., "Ablation of atrial fibrillation after the retirement age: considerations on safety and outcome," Journal of Interventional Cardiac Electrophysiology, vol. 28, no. 3, pp. 193-197, 2010. 


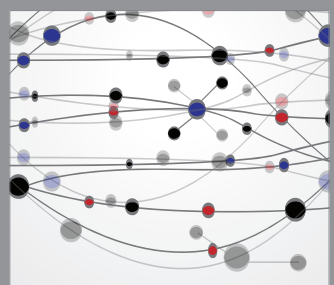

The Scientific World Journal
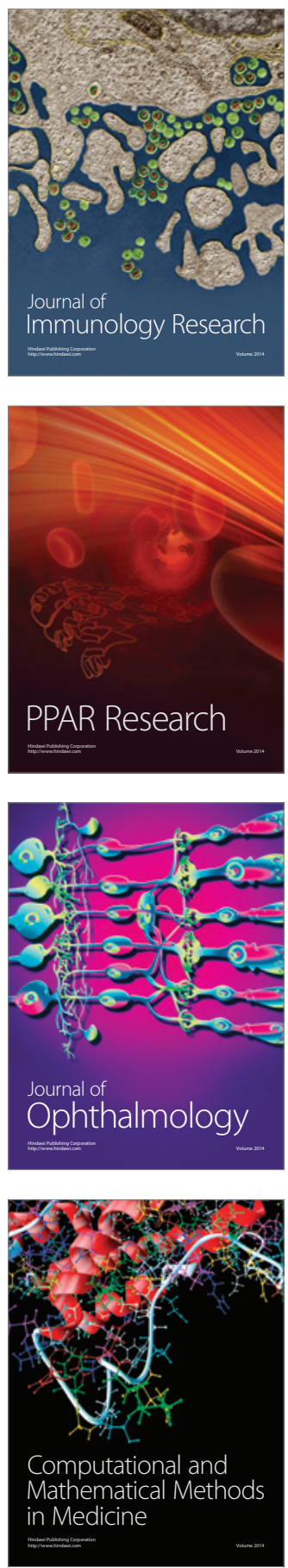

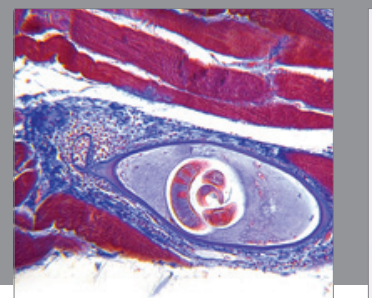

Gastroenterology

Research and Practice
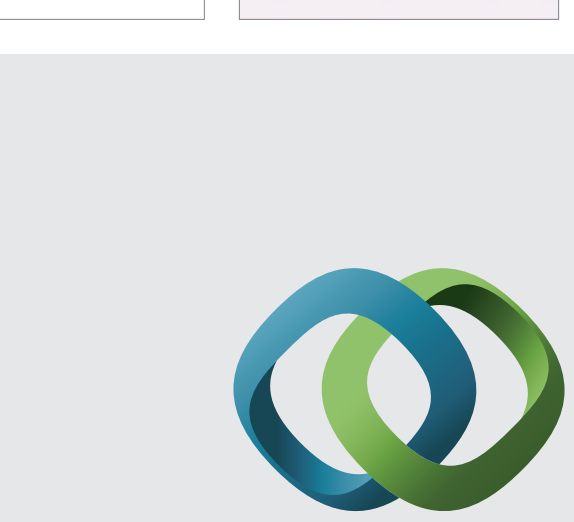

\section{Hindawi}

Submit your manuscripts at

http://www.hindawi.com
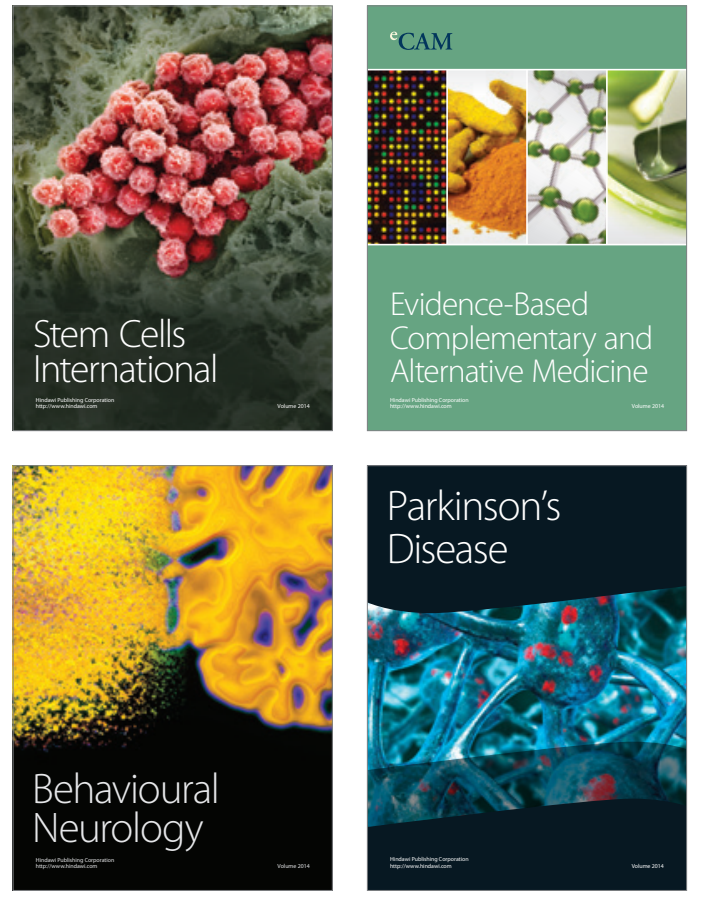
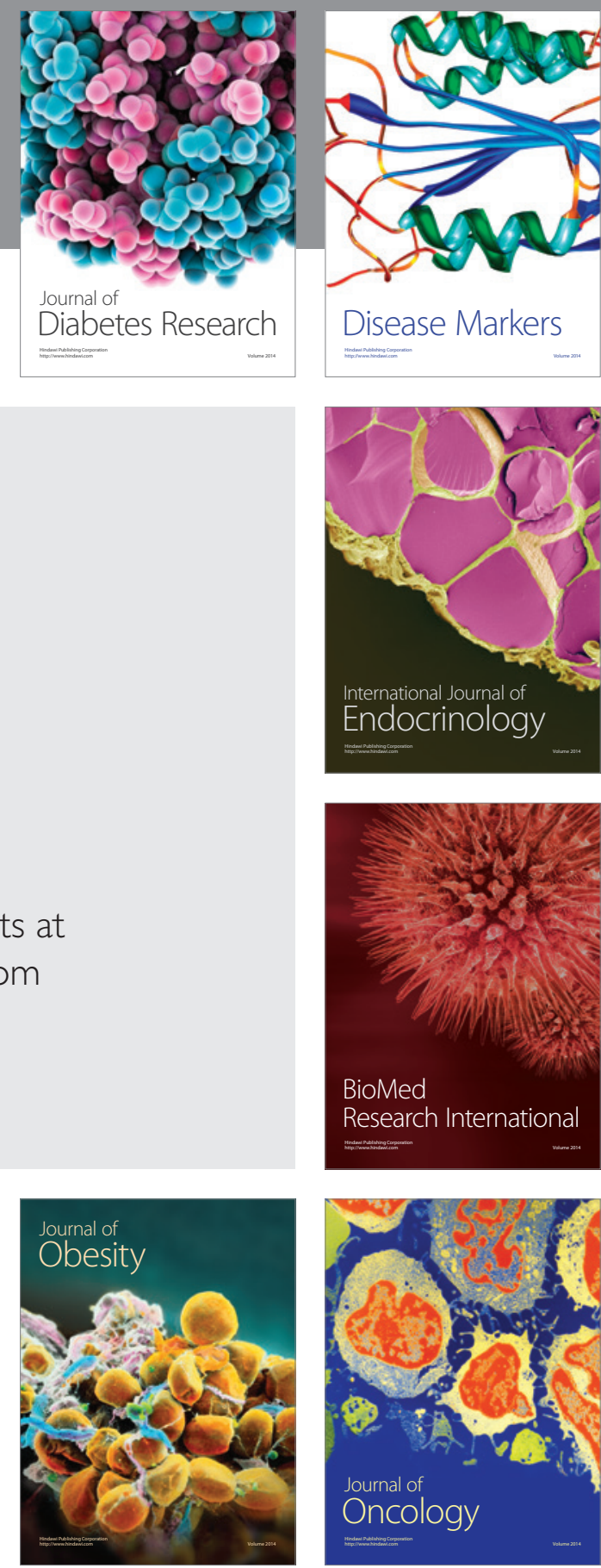

Disease Markers
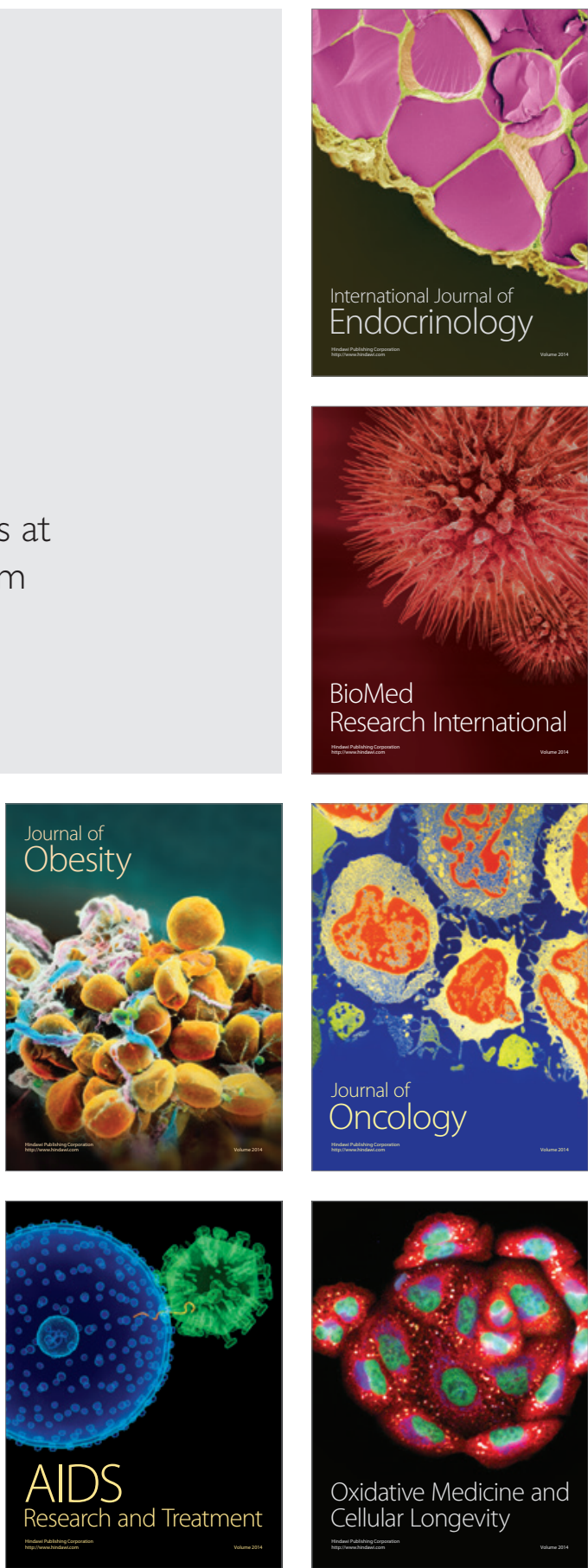